University of Tennessee Health Science Center UTHSC Digital Commons

$6-2000$

\title{
Functional Significance of the Upregulation of Adhesion Molecules on Irradiated Endothelial Cells
}

\author{
Balabhaskar Prabhakarpandian \\ University of Tennessee Health Science Center
}

Follow this and additional works at: https://dc.uthsc.edu/dissertations

Part of the Therapeutics Commons

\section{Recommended Citation}

Prabhakarpandian, Balabhaskar, "Functional Significance of the Upregulation of Adhesion Molecules on Irradiated Endothelial Cells" (2000). Theses and Dissertations (ETD). Paper 211. http://dx.doi.org/ 10.21007/etd.cghs.2000.0253.

This Thesis is brought to you for free and open access by the College of Graduate Health Sciences at UTHSC Digital Commons. It has been accepted for inclusion in Theses and Dissertations (ETD) by an authorized administrator of UTHSC Digital Commons. For more information, please contact jwelch30@uthsc.edu. 


\title{
Functional Significance of the Upregulation of Adhesion Molecules on Irradiated Endothelial Cells
}

\begin{abstract}
Ionizing radiation is a major therapy for cancer. Damage to the endothelium and upregulation of inflammatory responses are major side effects of radiotherapy, but the mechanisms behind these processes are not clear. A key component of the inflammatory response is leukocytes adhesion to the endothelium in a multi-step process involving leukocyte tethering to the endothelium, followed by rolling, firm adhesion/spreading and extravasation. Adhesion molecules mediate this process, particularly, Eselectin and ICAM-1, which are inducible adhesion molecules. E-selectin is involved in the initial tethering and rolling steps of the adhesion cascade while ICAM-1 appears to be involved in the latter steps. We have hypothesized that in response to irradiation, the endothelium becomes activated, increases its expression of adhesion molecules such as E-selectin and ICAM-1, and supports the increased interaction of leukocytes with the endothelium. To probe this hypothesis, we have investigated the expression of Eselectin and ICAM-1 on Human umbilical vein endothelial cells (HUVEC), human microvascular endothelial cells (HDMECs) and transformed microvascular endothelial cells (HMEC-1) at $5 \mathrm{hr}, 24 \mathrm{hr}, 48 \mathrm{hr}$ and $72 \mathrm{hr}$ post-irradiation. We have also developed an in vitro flow model to study the functional consequences of the radiation induced upregulation of adhesion molecules, primarily E-selectin and ICAM-1. Endothelial cells were grown in 35mm dishes and irradiated with a single dose of $10 \mathrm{~Gy}$. HL60 (human promyelocytic leukemia) cells were perfused over the irradiated (IR) endothelial cells in a parallel plate flow chamber at shear stress of $0.5-2.0$ dynes $/ \mathrm{cm} 2$. Flow cytometry analysis at $5 \mathrm{hr}, 24 \mathrm{hr}, 48 \mathrm{hr}$ and $72 \mathrm{hr}$ post-irradiation showed upregulation of E-selectin at $5 \mathrm{hr}$ post-IR only on HDMECs. ICAM- 1 was upregulated at $24 \mathrm{hr}$ (HDMECs), and $48 \mathrm{hr}$ (HUVECs and HMEC-1).

Flow assays revealed an increase in the rolling and adhesion of HL60 cells on $5 \mathrm{hr}$ post-IR HDMEC. No rolling was observed on HUVECs and HMEC-1 monolayers $5 \mathrm{hr}$ post-IR consistent with the absence of Eselectin from the flow cytometry data. Semi-static assays at $48 \mathrm{hr}$ post-IR on HUVECs showed an increase in the number of adherent cells. There was a radiation dose dependent ( $5 \mathrm{~Gy}$ vs. $10 \mathrm{~Gy}$ ) increase in the expression of adhesion molecules, which was significant at $72 \mathrm{hr}$ post-IR. Our findings suggest that irradiation selectively impacts the functional aspects of the inflammatory response.
\end{abstract}

\section{Document Type}

Thesis

\section{Degree Name}

Master of Science (MS)

\section{Program}

Biomedical Engineering

Research Advisor

Mohammad F. Kiani

\section{Keywords}

ionizing radiation, adhesion molecules, endothelium, inflammatory response, late effects

\section{Subject Categories}

Analytical, Diagnostic and Therapeutic Techniques and Equipment | Medicine and Health Sciences | Therapeutics 


\title{
FUNCTIONAL SIGNIFICANCE OF THE UPREGULATION OF ADHESION MOLECULES ON IRRADIATED ENDOTHELIAL CELLS
}

\author{
A Thesis \\ Presented for \\ The Graduate Studies Council \\ The University of Tennessee, Memphis
}

\begin{abstract}
In Partial Fulfillment
Of the Requirements for the Degree

Master of Science

In the Joint Graduate Program in Biomedical Engineering

From the University of Tennessee

and

The University of Memphis
\end{abstract}

By

Balabhaskar Prabhakarpandian

June 2000 
Copyright $@$ Balabhaskar Prabhakarpandian, 2000

All rights reserved 


\section{DEDICATION}

This thesis is dedicated to my parents

\section{Pankajam Pandian \& P. K. Pandian}

without whom I would have never achieved what I have. 


\section{ACKNOWLEDGMENTS}

I would like to thank my mentor and primary advisor, Mohammad F. Kiani, Ph.D., for his constant guidance, encouragement, and patience during the tenure of this work. I would also like to thank my other committee members, Douglas Goetz, Ph.D., and Thomas Merchant, Ph.D., D.O., for their continued assistance throughout this study. In addition, I would like to thank Waleed Gaber, Ph.D., for performing the irradiation procedures and Felecia Waller for help with the flow cytometry data. Thanks are also due to Research Associate (Michael Naimark) and other students in the lab, Vinh Nguyen and Hong Yuan for keeping the lighter atmosphere during work. Lastly, I would like to express my thanks and gratitude to my parents, brother (Deendayal Dinakarpandian), my sister-in-law (Chitra Dinakar) and my nephews (Akshay Dinakar and Bhavish Dinakar) for giving me the strength and support and keeping my spirits high during this endeavor. Funding for this study was provided by the National Institute of Health (NIH), School of Biomedical Engineering and Department of Radiation Oncology at The University of Tennessee, Memphis. 


\section{ABSTRACT}

Ionizing radiation is a major therapy for cancer. Damage to the endothelium and upregulation of inflammatory responses are major side effects of radiotherapy, but the mechanisms behind these processes are not clear. A key component of the inflammatory response is leukocytes adhesion to the endothelium in a multi-step process involving leukocyte tethering to the endothelium, followed by rolling, firm adhesion/spreading and extravasation. Adhesion molecules mediate this process, particularly, E-selectin and ICAM-1, which are inducible adhesion molecules. E-selectin is involved in the initial tethering and rolling steps of the adhesion cascade while ICAM-1 appears to be involved in the latter steps. We have hypothesized that in response to irradiation, the endothelium becomes activated, increases its expression of adhesion molecules such as E-selectin and ICAM-1, and supports the increased interaction of leukocytes with the endothelium. To probe this hypothesis, we have investigated the expression of E-selectin and ICAM-1 on Human umbilical vein endothelial cells (HUVEC), human microvascular endothelial cells (HDMECs) and transformed microvascular endothelial cells (HMEC-1) at $5 \mathrm{hr}, 24 \mathrm{hr}, 48$ $\mathrm{hr}$ and $72 \mathrm{hr}$ post-irradiation. We have also developed an in vitro flow model to study the functional consequences of the radiation induced upregulation of adhesion molecules, primarily E-selectin and ICAM-1. Endothelial cells were grown in 35mm dishes and irradiated with a single dose of $10 \mathrm{~Gy}$. HL60 (human promyelocytic leukemia) cells were perfused over the irradiated (IR) endothelial cells in a parallel plate flow chamber at shear stress of 0.5-2.0 dynes $/ \mathrm{cm}^{2}$. Flow cytometry analysis at $5 \mathrm{hr}, 24 \mathrm{hr}, 48 \mathrm{hr}$ and $72 \mathrm{hr}$ post-irradiation showed upregulation of E-selectin at $5 \mathrm{hr}$ post-IR only on HDMECs.

ICAM-1 was upregulated at $24 \mathrm{hr}$ (HDMECs), and $48 \mathrm{hr}$ (HUVECs and HMEC-1). 
Flow assays revealed an increase in the rolling and adhesion of HL60 cells on $5 \mathrm{hr}$ postIR HDMEC. No rolling was observed on HUVECs and HMEC-1 monolayers 5 hr postIR consistent with the absence of E-selectin from the flow cytometry data. Semi-static assays at $48 \mathrm{hr}$ post-IR on HUVECs showed an increase in the number of adherent cells. There was a radiation dose dependent (5 Gy vs. $10 \mathrm{~Gy}$ ) increase in the expression of adhesion molecules, which was significant at $72 \mathrm{hr}$ post-IR. Our findings suggest that irradiation selectively impacts the functional aspects of the inflammatory response. 


\section{Table of Contents}

Chapter 1. INTRODUCTION \& LITERATURE REVIEW 1

Ionizing Radiation 4

Side Effects of Radiation Therapy 6

$\begin{array}{ll}\text { Leukocyte Adhesion Cascade } & 7\end{array}$

$\begin{array}{ll}\text { Adhesion Molecules } & 10\end{array}$

Upregulation of Adhesion Molecules Following Irradiation 15

Chapter 2. OBJECTIVES 17

Specific Aims 17

Hypothesis 17

Key Questions 18

Chapter 3. MATERIALS AND METHODS 19

Experimental Design 19

$\begin{array}{ll}\text { Media } & 21\end{array}$

Antibodies and Cytokines $\quad 21$

Endothelial Cell Cultures $\quad 21$

HL60 Cells 23

Irradiation 23

Flow Cytometry 24

In Vitro Flow Chamber Assay 25

Statistical Analysis 28

$\begin{array}{ll}\text { Chapter 4. RESULTS } & 29\end{array}$

Morphology of Endothelial Cells Following Irradiation 30

Expression of E-selectin on Endothelial Cells 32

Expression of ICAM-1 on Endothelial Cells 35

In Vitro Flow Chamber Assay 40

Comparison of Different Doses 46 
Chapter 5. DISCUSSION 47

Comparison of Control Data with Literature 47

Effects of Ionizing Radiation $\quad 48$

Chapter 6. CONCLUSION 54

Chapter 7. FUTURE WORK $\quad 56$

List of References

APPENDIX 64

Steps in Running an In Vitro Flow Chamber Assay 65

VITA 66 


\section{LIST OF TABLES}

Table 4-1. Summary of the adhesion molecules being upregulated following irradiation

Table 4-2. Number of rolling and adherent HL60 cells on $5 \mathrm{hr}$ post-IR (10 Gy) HUVECs

Table 4-3. Number of adherent HL60 cells on 48 hr post-IR (10 Gy) HUVECs

Table 4-4. HL60 cells rolling and adhering on $5 \mathrm{hr}$ post-IR (10 Gy) HDMECs 


\section{LIST OF FIGURES}

Figure 1-1. Hypothetical growth curve for a human tumor, showing the long latent period prior to detection. From Tannock (76)

Figure 1-2. Relationship between age and cancer incidence. From Tannock (76)

Figure 1-3. Survival curves for some normal tissues. From Tannock (76)

Figure 1-4. Neutrophil adhesion cascade

Figure 1-5. Time course followed by three prominent adhesion molecules. From Bevilacqua et al. (9)

Figure 1-6. Schematic of the selectins. From Bevilacqua et al. (9)

Figure 1-7. Integrins and IgG superfamily molecules. From Bevilacqua et al. (9)

Figure 1-8. Adhesion molecules in the adhesion cascade

Figure 3-1. Experimental design of the study

Figure 3-2. Schematic of the flow chamber

Figure 3-3. Experimental setup of the flow chamber assay

Figure 4-1. Comparison of expression of ICAM-1 on HUVECs using $\mathrm{x}$-ray or gamma-radiation

Figure 4-2. Morphology of endothelial cells following activation and irradiation 
Figure 4-3. Flow cytometry plots showing expression of E-selectin on HUVECs

Figure 4-4. Expression of E-selectin post-IR (10 Gy) on HUVECs

Figure 4-5. Expression of E-selectin post-IR (10 Gy) on HMEC-1

Figure 4-6. Expression of E-selectin on 5hr post-IR (10 Gy) HDMECs

Figure 4-7. Flow cytometry plots showing expression of ICAM-1 on HUVECs

Figure 4-8. Expression of ICAM-1 on post-IR (10 Gy) HUVECs

Figure 4-9. Expression of ICAM-1 on post-IR (10 Gy) HMEC-1

Figure 4-10. Expression of ICAM-1 on post-IR (10 Gy) HDMECs

Figure 4-11. Flow cytometry plots for the expression of ligand of E-selectin on HL60 cells

Figure 4-12. Flow cytometry plot for the expression of ligands of ICAM-1 on HL60 cells

Figure 4-13. HL 60 cells rolling and adhering on 5 hr post-IL-1 $\beta$ HUVECs

Figure 4-14. HL60 cells rolling on 5 hr post-IR (10 Gy) HDMECs

Figure 4-15. HL60 cells adhering on 5 hr post-IR (10 Gy) HDMECs

Figure 4-16. Effect of dose on the expression of ICAM-1 post-IR on HUVECs 


\section{Chapter 1. INTRODUCTION \& LITERATURE REVIEW}

Cancer is the second leading cause of the death in prosperous countries around the world. In the United States 1 out of every 4 deaths is attributed to cancer. This year about 563,100 Americans are predicted to die of cancer (2). Additionally, about 1,221,800 people are expected to be diagnosed with cancer (2). With the major advancements in the field of surgical therapy, hormonal therapy, radiotherapy and chemotherapy most cancers can be cured if detected early. Cancer is a collective term for a group of diseases, which can be classically defined as an uncontrolled growth, and spread of abnormal cells". If the spread is not controlled, it can result in death.

The origin of the word cancer is credited to the Greek physician Hippocrates (460-370 B.C.), considered the "Father of Medicine." Hippocrates used the terms "carcinos" and "carcinoma" to describe non-ulcer forming and ulcer-forming tumors. In Greek these words refer to a crab, and hence most applicable to this disease because the finger like spreading projections from a cancerous mass suggest the shape of a crab. The oldest recorded reference to cancer (although the term cancer was not used) was in Egypt and dates back to approximately 1600 B.C.

In most cases tumor cells in a tumor are clones of single precursor cell (76). A tumor can be classified as benign (has not invaded neighboring tissue) or malignant (has invaded neighboring tissue). All tumors, benign and malignant, consist of proliferating cells that constitute the parenchyma, and supportive stroma made up of connective tissue and blood vessels. Tumors grow in an exponential phase (Figure1-1). It takes more time for a tumor to grow from a non-detectable size to a size that can be clinically detectable (1 to $10 \mathrm{~g}$ ) than to grow to a size that can kill the person $(1$ to $10 \mathrm{~kg})$. In many cases the cancerous cells in a tumor are 
dead or are in the process of dying. Small numbers of cells, however, continue to grow and these are the cells, which make the clinical treatment necessary.

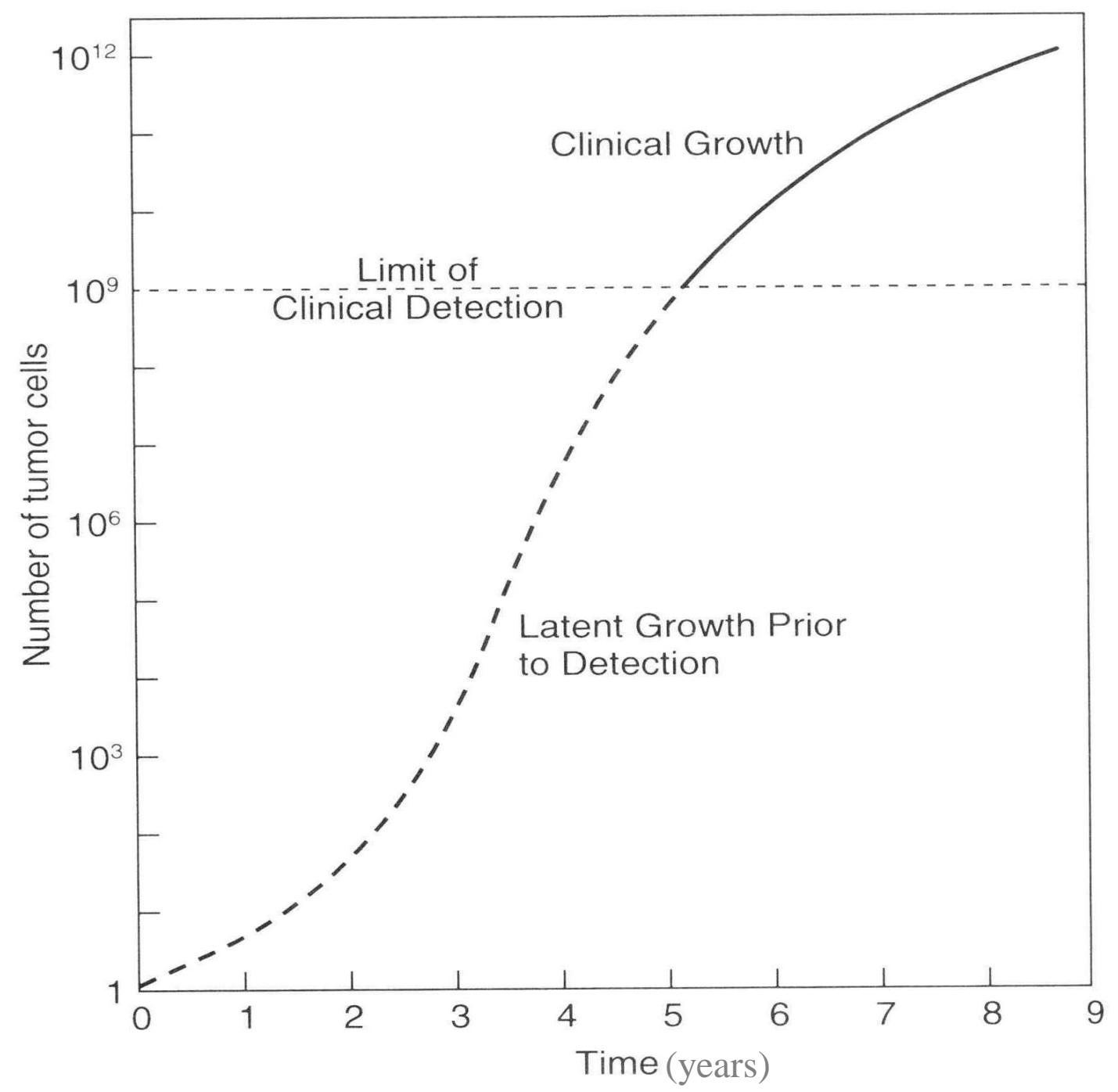

Figure 1-1. Hypothetical growth curve for a human tumor, showing the long latent period prior to detection. From Tannock. (76)

The microenvironment of a tumor is drastically different from that of normal cells.

Tumor vasculature has very few smooth muscle cells (sometimes none). Endothelial cells are very irregular (recently a cancer has been discovered where no endothelial cells are present (7)). 
The basement membrane is missing; vessels are tortuous with arteriovenous shunts and no defined hierarchy. The vascular oxygen supply to tumors is poorer than that of normal cells. The diffusion of $\mathrm{O}_{2}$ is limited to $70-150 \mu \mathrm{m}$, which is responsible for the hypoxic region in the tumors (76). Tumors also possess high interstitial pressure, have low $\mathrm{pH}$ and low $\mathrm{pO}_{2}$.

Tumors also differ from the normal cells in their biochemical (19) and genetic (17) makeup. In most tumors, chromosomal abnormalities can be seen. It takes on average five to seven mutations to transform a normal cell into a cancer cell. In our body, a spontaneous mutation occurs at a frequency of $10^{-6}$ to $10^{-7}$ per cell per generation. However, exposure to mutagens can increase the frequency by 10 to 100 folds. These mutagenesis can be due to viral carcinogenesis $(26,28)$, chemical carcinogenesis (58), radiation carcinogenesis (29), and chromosomal aberrations of the oncogenes $(12,17,80)$.

The consequence of chromosomal aberrations influences the function of two distinct classes of genes in human tumors: dominantly acting genes and tumor suppressor genes (80). When an oncogene becomes inappropriately activated, it signals the cells to proliferate, thus leading to the formation of a tumor. This is known as a dominantly acting gene. The body also has genes known as tumor suppressor genes that when functioning normally inhibit cell proliferation. Loss or inactivation of these genes can result in cell proliferation, eventually leading to a tumor.

The probability of developing a tumor increases exponentially with age (Figure1-2). Once a tumor starts to grow rapidly in the body, the physicians have three primary options to get rid of the tumor: surgical removal, treatment with chemotherapy or treatment with ionizing radiation. Ionizing radiation is the second most common mode of treatment following surgery. 


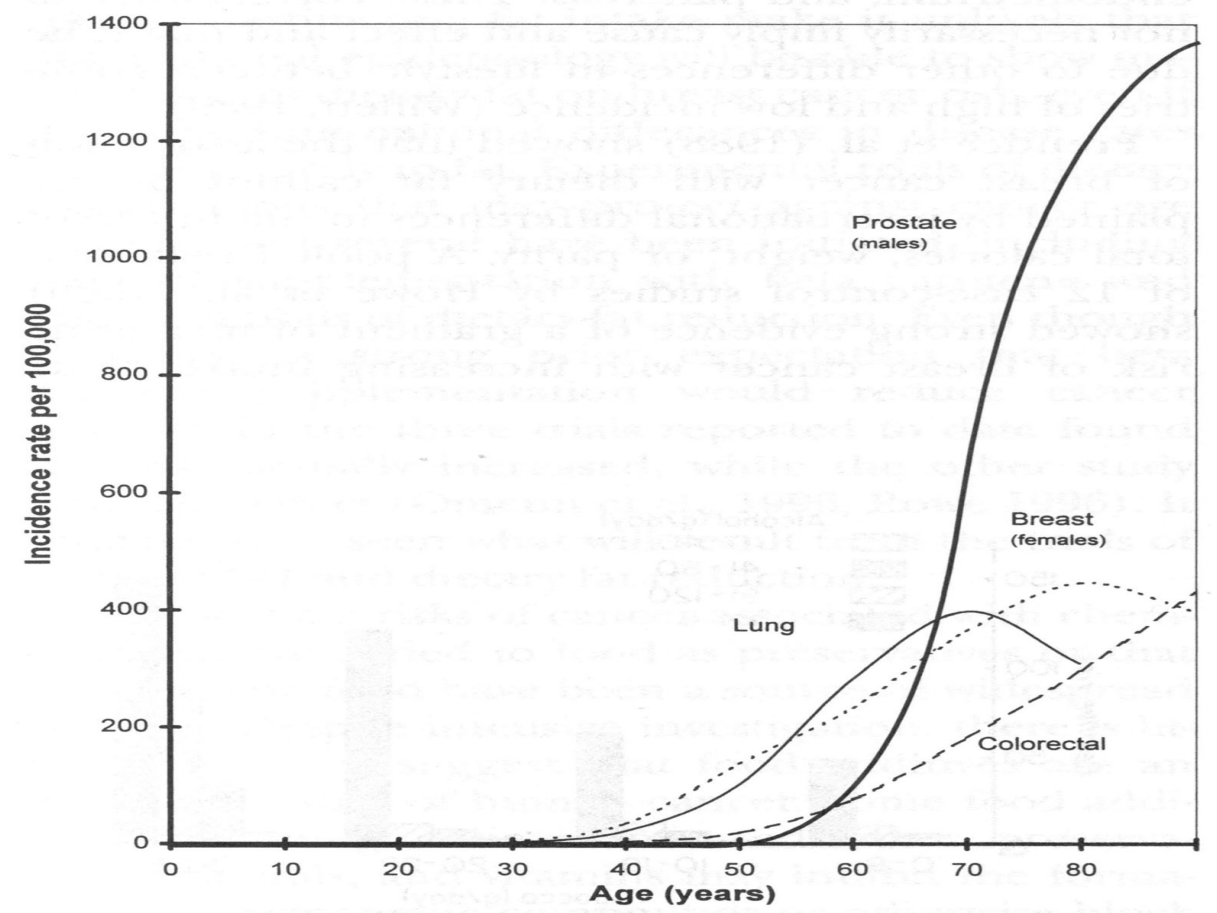

Figure 1-2. Relationship between age and cancer incidence. From Tannock (76).

\section{Ionizing Radiation}

X-rays were discovered in the year 1895 by German physicist Wilhelm Conrad

Roentgen. Parallel to this was the discovery of radioactivity in 1898 by Becquerel, which laid the foundation for gamma rays. The first famous biological experiments, which laid the foundation for clinical radiation therapy, were performed in 1920s and 1930s in Paris, where testes of rams were irradiated with x-rays. It proved to be impossible to sterilize the animals in a single dose without a severe reaction to the skin of the scrotum. However, on fractionating the total dose over a period of time, sterilization could be achieved with minimal skin damage. The basis for this phenomenon was that the testis is a model for a rapidly growing tumor, while the skin represented the normal tissue response to radiation damage. Both X-rays and gamma rays 
constitute part of the continuos spectrum of electromagnetic radiation. All types of radiation can be considered as moving packets (quanta) of energy called photons. When absorbed by the medium through which they pass, both x-rays and gamma rays give up energy to produce fast moving electrons by the Compton, photoelectric effect or the pair production processes (44). Xrays are produced extranuclearly while gamma rays are produced intranuclearly, but they do not differ in nature or properties. Both eventually cause damage in the same manner with the release of localized high energy. The raising of an electron in an atom or molecule to a higher energy level without the actual ejection of that electron is called excitation. If the radiation has sufficient energy to eject one or more orbital electrons from the atom or molecule, the process is known as ionization and the radiation is called ionization radiation.

The important characteristic of ionizing radiation is to locally release large amount of energy. The energy dissipated is more than enough to break strong chemical bonds. Most of the energy absorbed produces ions and reactive radicals that interact with biochemical processes in the body, making them shift towards the apoptotic pathway. It has been estimated that approximately 1 x $10^{5}$ ionization's can occur within the cell per gray of radiation dose absorbed, that can lead to approximately 200 single stranded and 25 to 50 double stranded breaks in the DNA which trigger apoptosis (76). Radiation damages both tumors and normal tissue, but in general tumors are more susceptible to radiation damage. At low or fractionated doses of radiation, most of the damaged tissues can repair themselves. Those tissues that cannot do so either go into the apoptotic process or develop in an irregular manner leading to the late side effects. Thus, radiation can cause either temporary or permanent loss of function in normal tissues. Figure 1-3 shows the survival curves for some normal tissues in mice. 


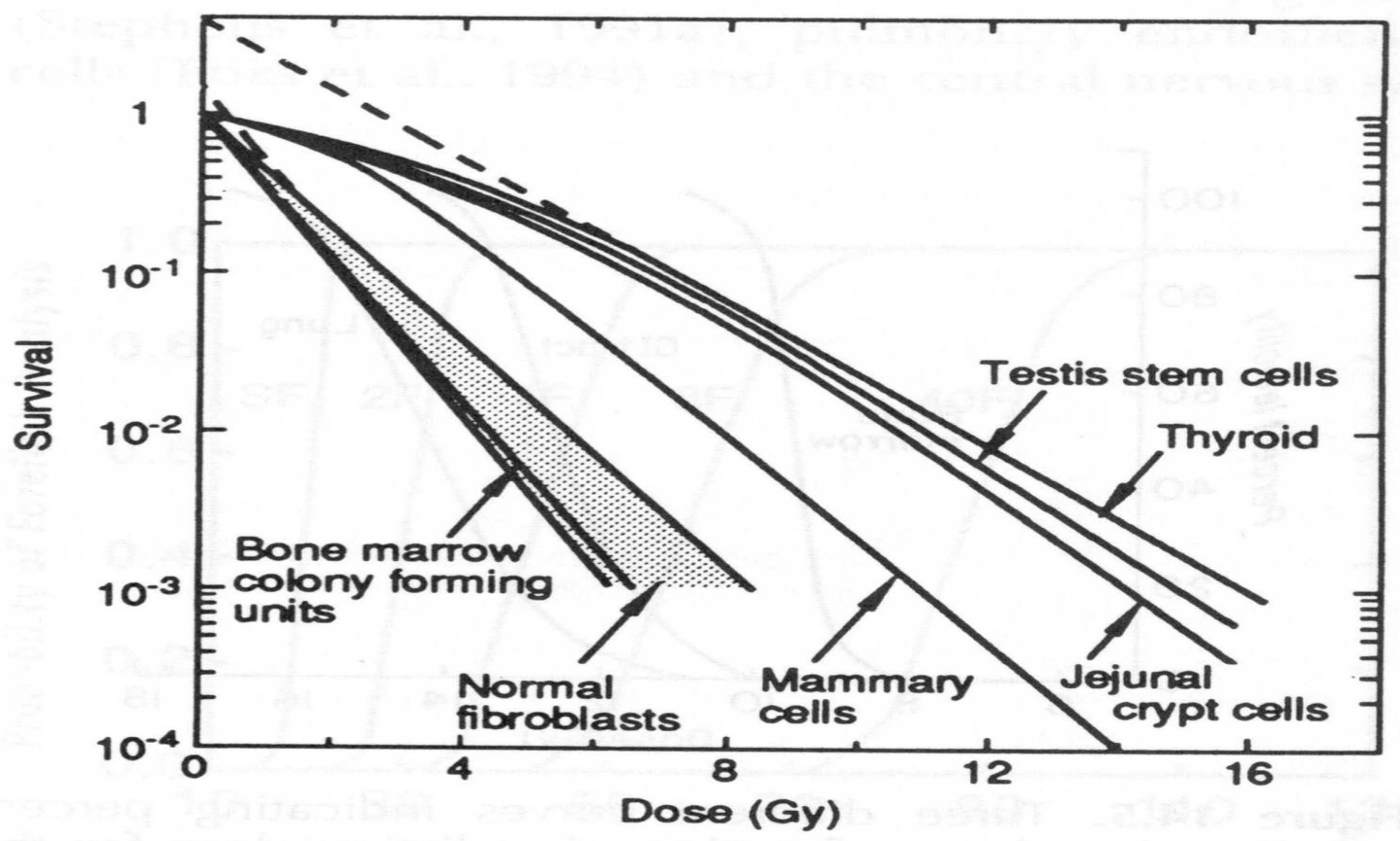

Figure 1-3. Survival curves for some normal tissues. From Tannock (76)

The energy range most commonly used in clinical therapy is $6 \mathrm{MeV}$ to $20 \mathrm{MeV}$. The radiation dose is measured in terms of amount of energy (joules) absorbed per unit mass ( $\mathrm{kg}$ ) and is quoted in grays $(1 \mathrm{~J} / \mathrm{kg})$. The role of radiation therapy is to maximize tumor kill and minimize normal tissue damage and this aspect forms the basis for the dose limitation during radiotherapy.

\section{Side Effects of Radiation Therapy}

Patients receiving radiation therapy are at risk of developing complications due to radiation damage of normal tissues. These effects can be divided into early or acute responses, which occur within days to weeks of treatment, and late effects, which may take months to develop. Acute responses occur primarily on tissues that divide rapidly such as the cells of the skin, intestine, etc. Late effects tend to happen in tissues where the cells divide either slowly 
(e.g., cells of liver or kidney, endothelial cells) or not at all (e.g., central nervous system or muscle).

Radiation has been found to increase the permeability of vessels (13). Radiation causes both structural and functional changes in the vasculature (5), which may lead to fibrosis (61). In a number of normal tissues upregulation of cytokines (IL family, TGF- $\beta$, TNF- $\alpha$, PDGF) following ionizing radiation has been shown $(6,18,49,68)$. These observations suggest that cytokines may contribute to the pathological conditions arising at later time points postirradiation. One interesting feature that is pertinent to this study is the increased leukocyteendothelial interactions following radiation mediated by adhesion molecules. Before this post radiation phenomenon is discussed we will review the leukocyte adhesion cascade.

\section{Leukocyte Adhesion Cascade}

Leukocytes are in a common sense the bodyguards of our body protecting us from bacteria, viruses and other pathogens. Most of this defense mechanism occurs at the tissue level when leukocytes migrate to the site of infection/damage and overcome the pathogen. In this

process however, the normal tissue is also damaged which in time repairs itself. After activation, the first step in this pathway is the leukocyte adhering to the endothelium. This leukocyte adhesion to the endothelium is an important aspect of many physiological and pathophysiological processes $(15,45,73,74)$. It has been shown that the leukocyte adhesion to the endothelium is a multistep process (51).

After upregulation of adhesion molecules on endothelial cells, circulating leukocytes interact with the vessel wall and slow down their velocity initiating a phenomenon called rolling characterized by the ability of leukocytes to roll on the endothelium. Leukocytes then firmly 
adhere to the endothelium and start to extravasate into the tissues by migrating through the endothelium (Figure 1-4). These processes of leukocyte-endothelium interactions are mediated by a series of receptor ligand interactions present on the endothelium and the leukocytes.

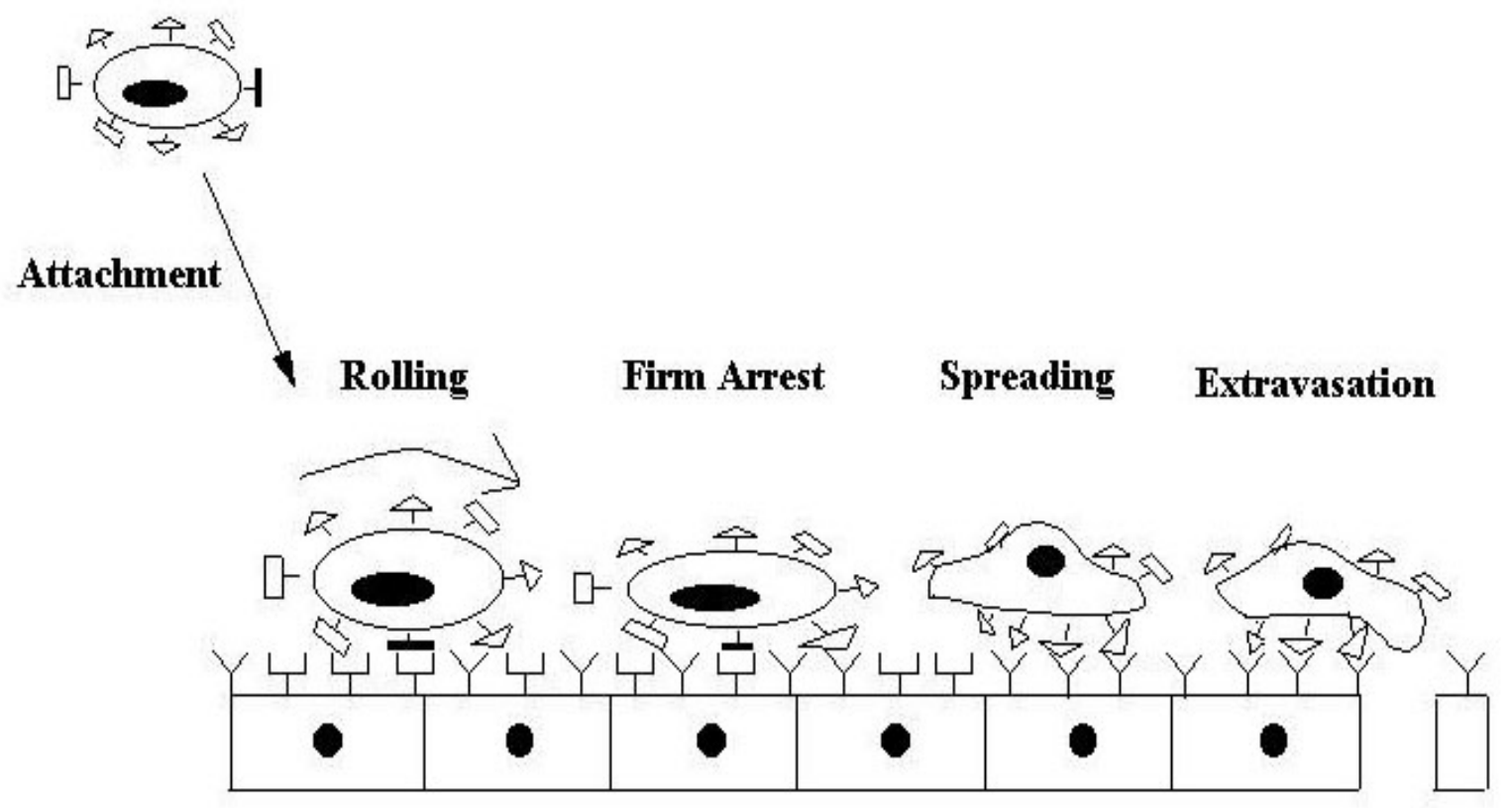

Figure 1-4. Neutrophil adhesion cascade.

Very rarely does one see the leukocytes rolling, adhering and extravasating on normal endothelium. Usually, the adhesion cascade depends on the activation of the endothelium. Activation of the endothelium increases the expression of certain adhesion molecules. These adhesion molecules mediate the interaction of the leukocytes by interacting with their counter ligands on the leukocytes. Primarily the adhesion molecules upregulated on the endothelium are E-selectin, ICAM-1 and VCAM-1 (9). The endothelium can be activated in several ways (55). A typical time course followed by the molecules after activation by IL-1 is depicted in Figure 1-5. 


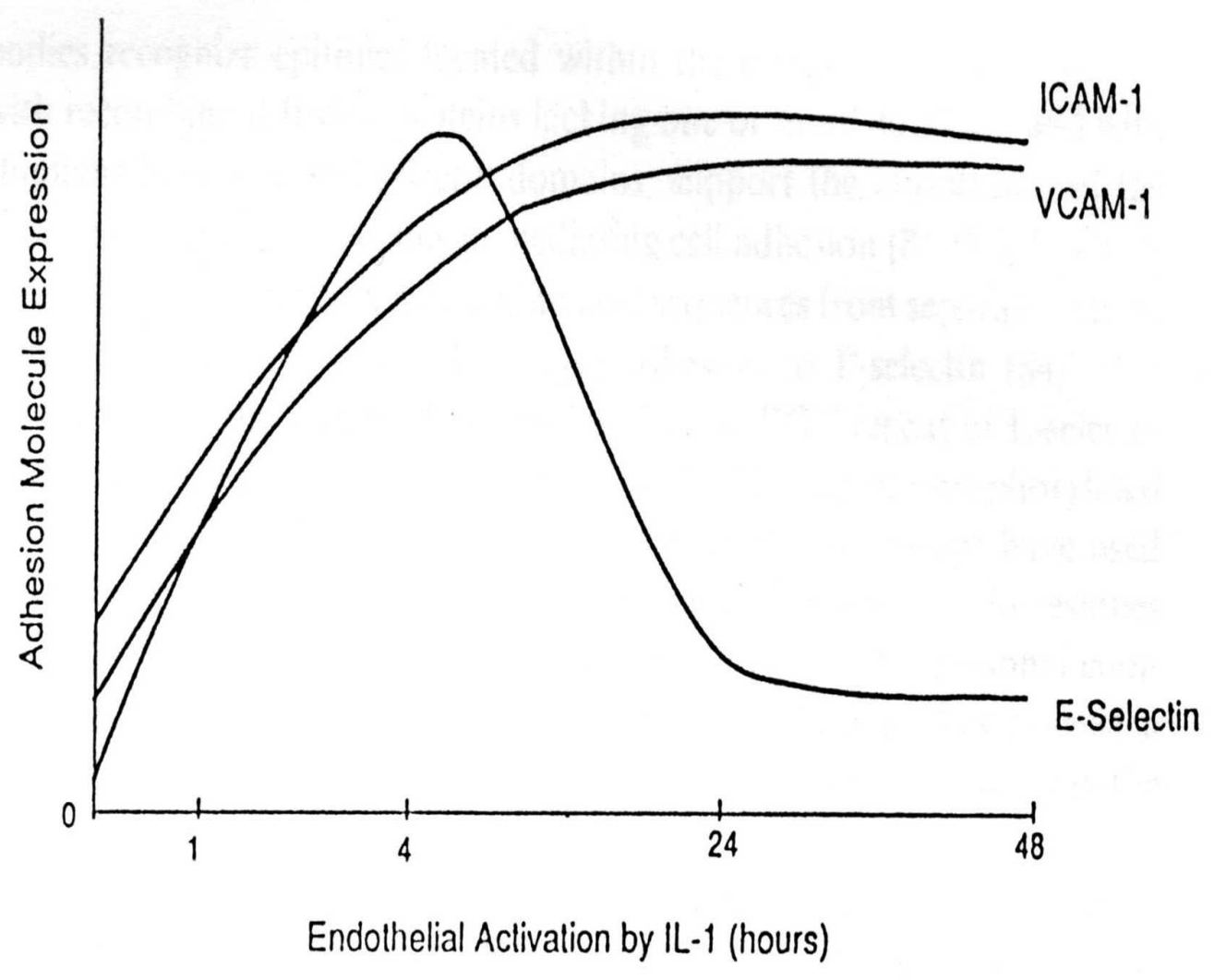

Figure 1-5. Time course followed by three prominent adhesion molecules. From Bevilacqua et al. (9)

Leukocytes are activated upon coming in contact with the endothelium. This activation is characterized by a conformational change of the $\beta_{2}$ intergrin from a non-active form to an active form (23). This conformational change makes the leukocytes more adhesive to their counter receptors ICAM-1 (23) expressed by the endothelial cells. These conformation changes were detected by the use of monoclonal antibodies (23). The adhesion molecules involved in the adhesion cascade are described in detail in the following section. 


\section{Adhesion Molecules}

Adhesion molecules, which play a major role in the leukocyte-endothelial interactions, belong to the families of Selectins, Immunoglobulin and Integrins.

\section{Selectins:}

Selectins are known to be responsible for mediating the attachment and rolling of leukocytes onto the endothelium $(1,50,52)$. The selectins have a structure characterized by an amino terminus ( $\mathrm{Ca}^{+}{ }^{+}$-dependent lectin-like domain), an epidermal growth factor (EGF) like domain, a variable number of consensus repeats similar to those appearing in complementregulatory proteins, a transmembrane domain and a cytoplasmic tail (9). There are three types of Selectin: E, P and L-selectin. A generalized schematic of their structures is shown in Figure 1-6.
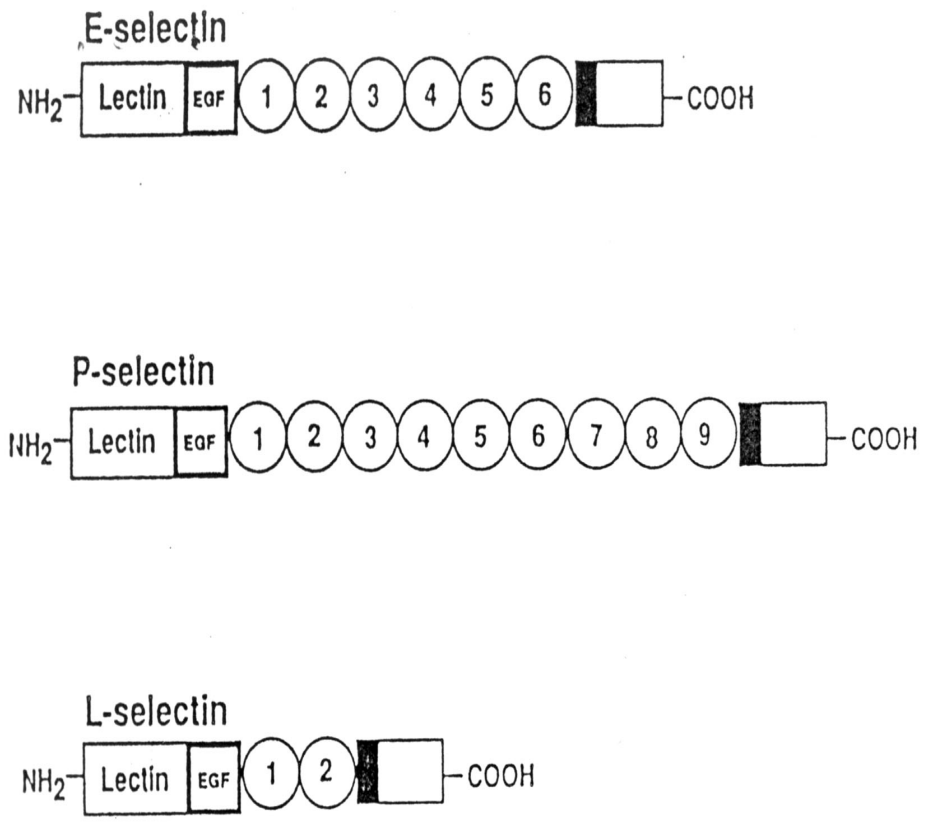

Figure 1-6. Schematic of the selectins. From Bevilacqua et al. (9) 


\section{E-Selectin:}

A member of the Selectin family, E-Selectin (CD62E) is a 107 - $115 \mathrm{kDa}$ cell surface glycoprotein. E-selectin is an inducible adhesion molecule and is upregulated following activation by IL-1, TNF- $\alpha$ and LPS $(10,11)$. E-selectin expression requires de novo protein synthesis $(10,11)$. Previous studies show that E-selectin mediates leukocyte attachment and rolling under flow conditions $(1,52)$. The counter ligands for E-selectin present on the leukocytes are P-selectin glycoprotein ligand-1 $(34,59)$, a $106 \mathrm{kDa}$ protein commonly called as PSGL-1 and L-Selectin $(64,65)$ present on almost all types of leukocytes. Structural study of these ligands has shown that all of them share a common glycan the SLe ${ }^{\mathrm{x}}$ type. SLe ${ }^{\mathrm{x}}$ has been found to mediate adhesion of leukocytes to E-selectin $(14,57)$.

\section{P-Selectin:}

Human P-Selectin (CD62P) is a cell surface glycoprotein expressed by activated platelets and endothelial cells. P-Selectin is translocated to the cell surface within minutes following stimulation. P-selectin can mediate the attachment and rolling of leukocytes to the endothelium $(51,54,59)$. The primary ligand for P-Selectin is PSGL-1 (59). PSGL-1 is found universally on almost all the types of leukocytes and is located on the microvilli (59).

\section{L-Selectin:}

Human L-Selectin (CD62L) is a cell surface glycoprotein expressed constitutively on a variety of leukocytes. Two forms of L-Selectin have been reported, apparently arising as a result

of post-translational modifications. The lymphocyte form shows an apparent molecular weight of $74 \mathrm{kDa}$, while the neutrophil form is $90-100 \mathrm{kDa}$ and the monocytes form is $110 \mathrm{kDa}$. L-selectin 
is constitutively expressed on a variety of leukocytes and is localized on the microvilli tips (65).

L-selectin is shed from activated leukocytes (45). The ligands for L-selectin are sgp50, sgp90 (CD34), GlyCAM-1, MadCAM-1 and E-selectin. L-selectin has been implicated in playing a role in the attachment and rolling of leukocytes to E-selectin under flow $(52,64)$.

\section{Immunoglobulins (IgG) family:}

All the member of this immunoglobulin family (IgG family) have an immunoglobulin like domain (79). The domain consists of 90-100 amino acids arranged in two sheets of antiparallel $\beta$ strands and stabilized by disulfide bonds (79). The molecules involved in the adhesion cascade are Intercellular Adhesion Molecules (ICAM-1 and ICAM-2) and Vascular Cellular Adhesion Molecule (VCAM-1). These molecules play a major role in the firm adhesion and extravasations of leukocytes $(55,73)$. Both ICAM-1 and ICAM-2 are constitutively expressed on the endothelial cells (15). However, ICAM-2 is not modulated by cytokines (15). The primary ligand for ICAM-2 has been found to be $\beta_{2}$ integrin (15).

VCAM-1 is upregulated by cytokines and is a ligand of LFA-1 and Mac-1 (21). VCAM-1 levels are elevated at $24 \mathrm{hr}$ and return to base line by $48 \mathrm{hr}$. The corresponding ligands for VCAM-1 are $\beta_{1}$ integrin, VLA-4 $\left(\alpha_{4} \beta_{1}\right)$ and $\alpha_{4} \beta_{7}$ (73).

ICAM-1 is constitutively expressed on endothelial cells, epithelial cells, lymphocytes and fibroblasts (56). ICAM-1 is expressed constitutively at low levels on endothelial cells (9). Upon activation of the endothelium, the expression of ICAM-1 increases significantly (9). ICAM-1 levels reach peak values by $24 \mathrm{hr}$ and remain high for several days (9). The ligands for ICAM-1 are $\beta_{2}$ integrins, LFA-1 and Mac-1 (9). 


\section{Integrins:}

Integrins are involved in several physiological processes integral to the normal functioning of the body (69). They also are important players in the adhesion cascade of the leukocytes. Integrins have three main structural motifs; a $\alpha$ subunit I-domain, $7 \mathrm{NH}_{2}$-terminal repeats and a $\beta$ subunit - I domain (53). The $\alpha$ subunit I-domain has a dinucleotide binding fold and a $\beta$ sheet surrounded by $\alpha$ helices (53).

The subunits, $\alpha$ and $\beta$ are related both in terms of structure and function (53). The integrins differ mostly in the make-up of the $\beta$ chain (22). This chain helps in distinguishing between different integrins. The $\beta_{2}$ subunit has several features including: a 769 amino acid sequence with an integral membrane protein, an extracellular domain with six N-glycosylation sites, a transmembrane domain and a cytoplasmic domain (46). $\beta_{2}$ is the integrin that plays a dominant role in the interaction of leukocytes to the endothelium. They are also called leukocyte integrins as they are only expressed on leukocytes (72). $\beta_{2}$ integrin include LFA-1 (CD11a/CD18), Mac-1 (CD11b/CD18), p150, 95 (CD11c/CD18) and the latest addition in the group is $\alpha_{D} / \beta_{2}$ (77). Both LFA-1 and Mac-1 are the major players in the adhesion cascade (46). LFA-1 is a heterodimer protein made up of a $\alpha_{1}$ chain and a $\beta_{2}$ chain (56). Mac-1 is a heterodimer consisting of $\alpha_{m}$ chain and $\beta_{2}$ chain. Mac-1 plays a similar role as that of LFA-1 in the adhesion cascade by binding to ICAM-1. ICAM-1 and ICAM-2 are ligands for LFA-1. The ligand for Mac-1 is ICAM-1 $(24,25)$ and E-selectin has been suggested to interact with Mac-1 $(3,48)$. Schematic view of the integrins and the $\operatorname{IgG}$ superfamily adhesion molecules is summarized in Figure 1-7. 


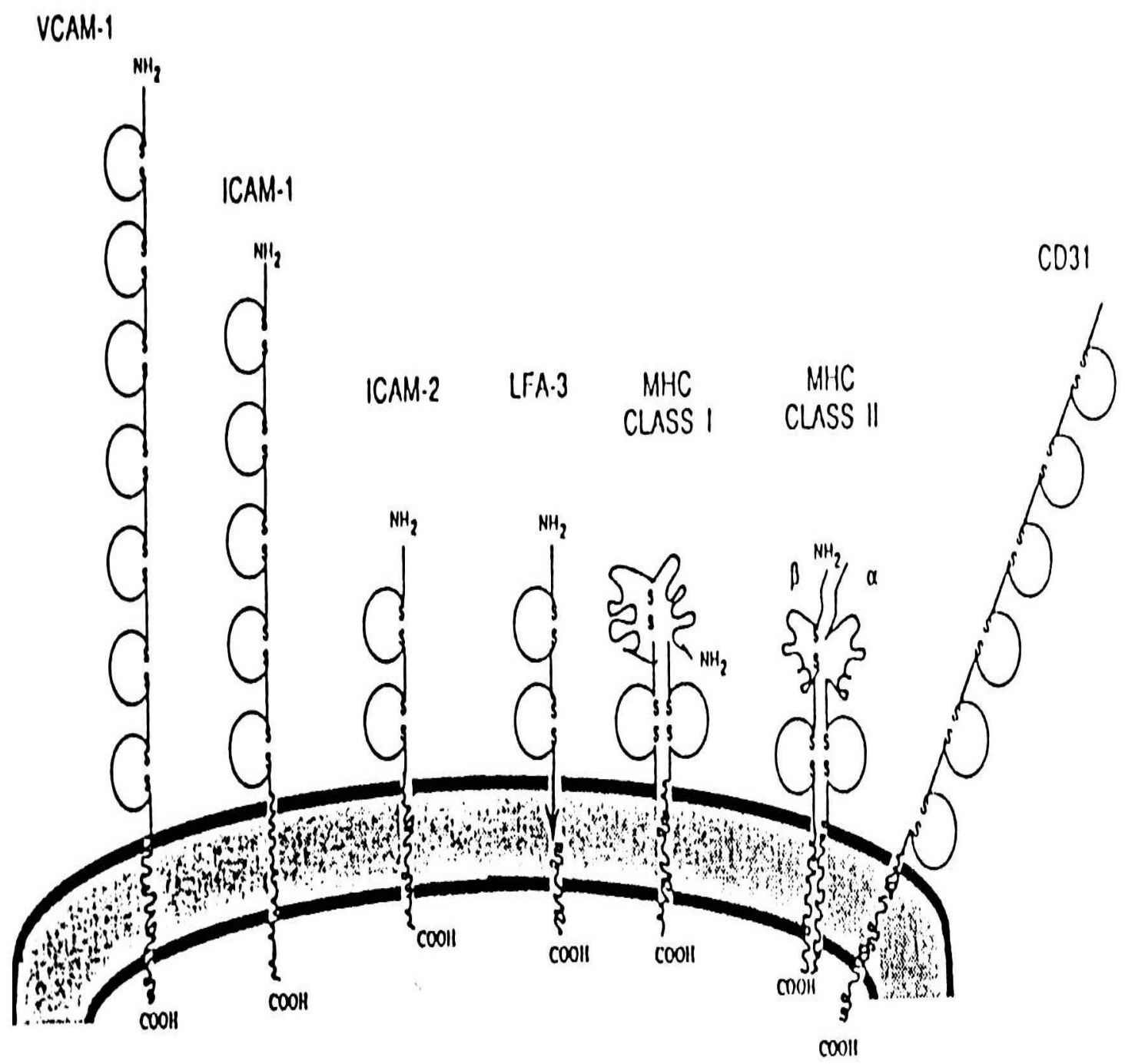

Figure 1-7. Integrins and IgG superfamily molecules. From Bevilacqua et al. (9)

Without the interactions of these adhesion molecules, the leukocyte adhesion cascade cannot function. In summary, the selectins (E, P and L) mediate the leukocyte rolling on the endothelium in interactions with PSGL-1. Firm adhesion is then mediated by the Integrins $\left(\beta_{2}\right)$ and the IgG family (ICAM-1, ICAM-2). Figure 1-8 summarizes the leukocyte adhesion cascade. 


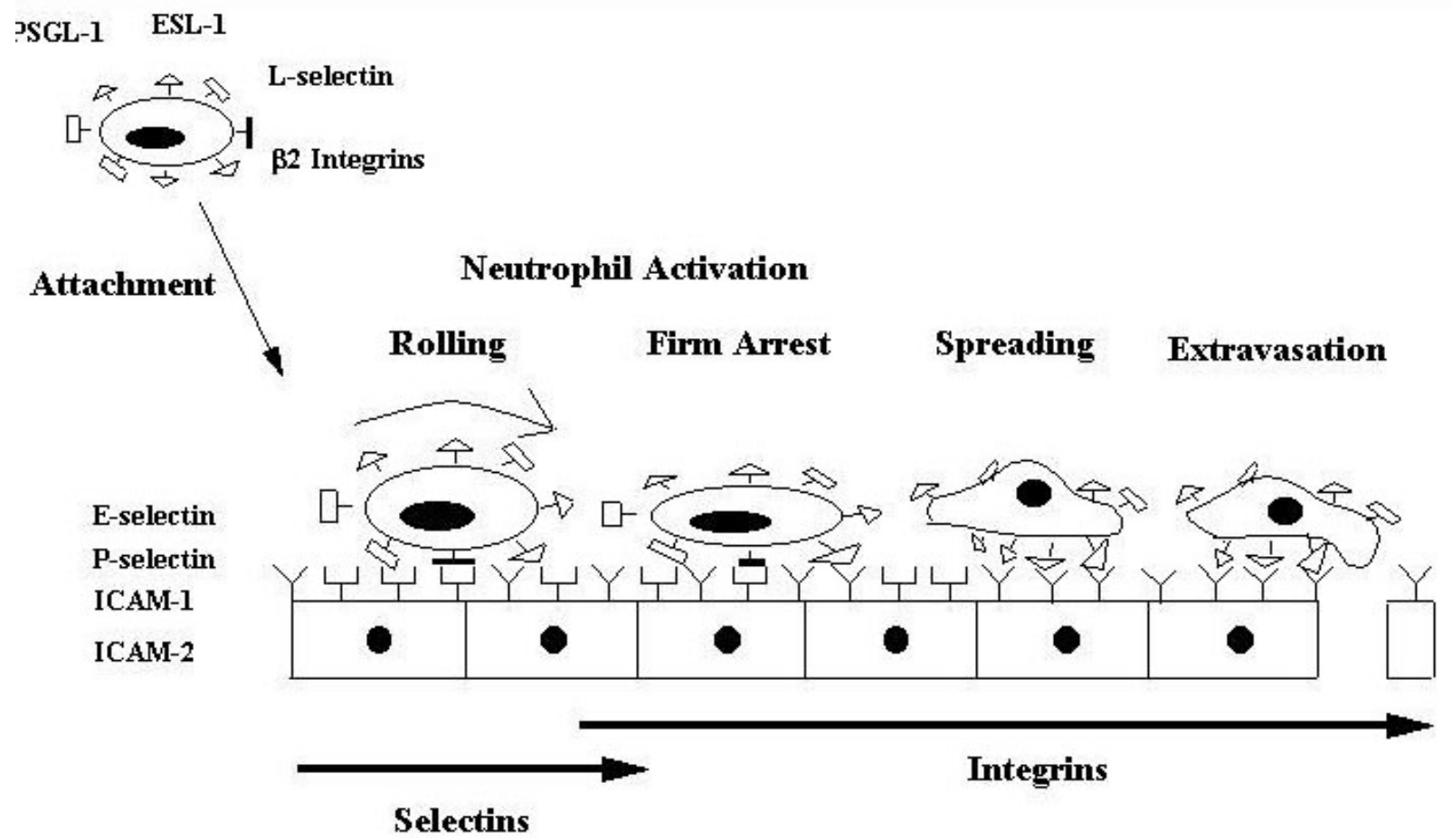

Figure 1-8. Adhesion molecules in the adhesion cascade.

\section{Upregulation of Adhesion Molecules Following Irradiation}

There has been increased interest in the upregulation of adhesion molecules following radiation during the last decade. Investigators have shown the upregulation of adhesion molecules, primarily E-selectin $(35,36,37,41,42)$ and ICAM-1 $(4,30,31,38,39,42)$ following irradiation of human endothelial cells. Hallahan et al. reported that E-selectin is upregulated as early as $2 \mathrm{hr}$, post-irradiation (IR) reaching a peak in $6 \mathrm{hrs}$ and returns to baseline by $24 \mathrm{hrs}$ $(35,36)$ on human umbilical vein endothelial cells (HUVECs). Heckmann et al. reported that the mRNA levels of E-selectin and ICAM-1 are upregulated significantly at $24 \mathrm{hr}$ post-irradiation (42) on human dermal microvascular endothelial cells. ICAM-1 is found to be upregulated at 16 hr post-irradiation reaching peak values at $24 \mathrm{hrs}$ and remains elevated until $48 \mathrm{hrs}$ (36) on 
HUVECs from the data of Hallahan et al. In contrast to this result, Gaugler et al. also working on HUVECs observed the presence of ICAM-1, and not E-selectin, post-irradiation (31). ICAM-1 was upregulated at $48 \mathrm{hr}$ post-IR and the levels remained high as long as 10 days post-IR (31). In vivo studies on the expression of adhesion molecules by Hallahan et al. have shown the presence of both E-selectin and ICAM-1 in the lungs of mice following irradiation (39). ICAM-1 mRNA has also been reported to be upregulated in human skin cultures $(4,8)$, and dermal endothelial cells (42) following irradiation.

Recently P-selectin has been found to be accumulated in the lumen of tumor blood vessels following radiation (40). Use of monoclonal antibodies to P-selectin and ICAM-1 in a rat model showed decrease in the number of rolling and firmly adhering leukocytes (63) after irradiation. Although upregulation of adhesion molecules in response to radiation have been reported, the functional consequence of the presence of E-selectin and ICAM-1 following irradiation has not been studied. Secondly, there have been controversial results regarding the expression of adhesion molecules based on the cell type (microvascular vs. large vessels) and radiation source (x-ray vs. gamma radiation).

In the current study, we investigated the functional consequences of the upregulation of the adhesion molecules after irradiation using an in vitro flow chamber. Endothelial cells from microvessels and large vessels irradiated with $\mathrm{x}$-ray or gamma were compared for the expression of adhesion molecules. HL60 cells, which have become a standard substitute for leukocytes in experiments were used to quantify leukocyte-endothelium interactions following radiation damage under conditions of flow. 


\section{Chapter 2. OBJECTIVES}

Ionizing radiation is a major treatment therapy for the treatment of cancer. Damage to the endothelium and inflammatory responses are the major side effects of radiotherapy, but the mechanisms behind these processes are not clear. Over the last decade, much has been learned about the inflammatory process in general. Consideration of these findings can give insight into the cellular and molecular mechanisms, which may govern tissue damage in response to irradiation.

\section{Specific Aims}

The main objective of the research presented here was to quantify the expression of adhesion molecules on the endothelium following ionizing radiation and to determine functional significance of the upregulation of these molecules in an in vitro flow chamber model.

\section{Hypothesis}

We hypothesize that exposure to ionizing radiation during radiotherapy activates the normal endothelium, which leads to the increase in expression of adhesion molecules such as Eselectin and ICAM-1, and supports the increased interaction of leukocytes and endothelial cells. This increased interaction leads to leukocytes extravasating into the tissues and mediating damage. Understanding of the functional interactions between the molecules can lead to reduction in the damage to the normal tissue. 


\section{Key Questions}

1. What adhesion molecules are upregulated on the endothelial cells following exposure to ionizing radiation?

2. Is the upregulation of adhesion molecules radiation dose dependent ?

3. What is the functional significance of the upregulation of these molecules in the interaction of leukocytes and the endothelium?

4. Do endothelial cells from different parts of the body react differently to ionizing radiation?

5. What is the effect of shear stress on the interaction of the leukocytes with the radiation activated endothelium? 


\section{Chapter 3. MATERIALS AND METHODS}

The methods described herein were used to quantify the expression of adhesion molecules on the irradiated endothelium and the functional consequence of their interactions with leukocytes. An in vitro flow chamber was developed to model the in vivo blood flow conditions.

\section{Experimental Design}

Three different types of endothelial cell cultures were used to study the expression of adhesion molecules following ionizing radiation. The endothelial cell cultures were human umbilical vein endothelial cells (HUVECs), human dermal microvascular endothelial cells (HDMECs) and HMEC-1 which is the transformed immortalized progeny of HDMECs. All the experiments were conducted at the following passages of the endothelial cells; HUVECs (P3P6), HDMECs (P4-P7) and HMEC-1 (P21-P26).

The endothelial cells were irradiated with a single dose of 10Gy (x-ray or gammaradiation). It has been shown that a dose of 5Gy or 10Gy produces observable changes in the normal tissue microvasculature (5). Irradiated HUVECs and HMEC-1 were observed at $5 \mathrm{hr}$, 24hr, $48 \mathrm{hr}$ and $72 \mathrm{hr}$ post-IR for the expression of adhesion molecules. HDMECs were analyzed at $5 \mathrm{hr}, 24 \mathrm{hr}$ and $48 \mathrm{hr}$ post-IR. Non-irradiated cells served as negative controls and IL-1 $\beta$ activated endothelial cells served as positive controls for the expression of adhesion molecules. The experimental design is shown schematically in Figure 3-1. 


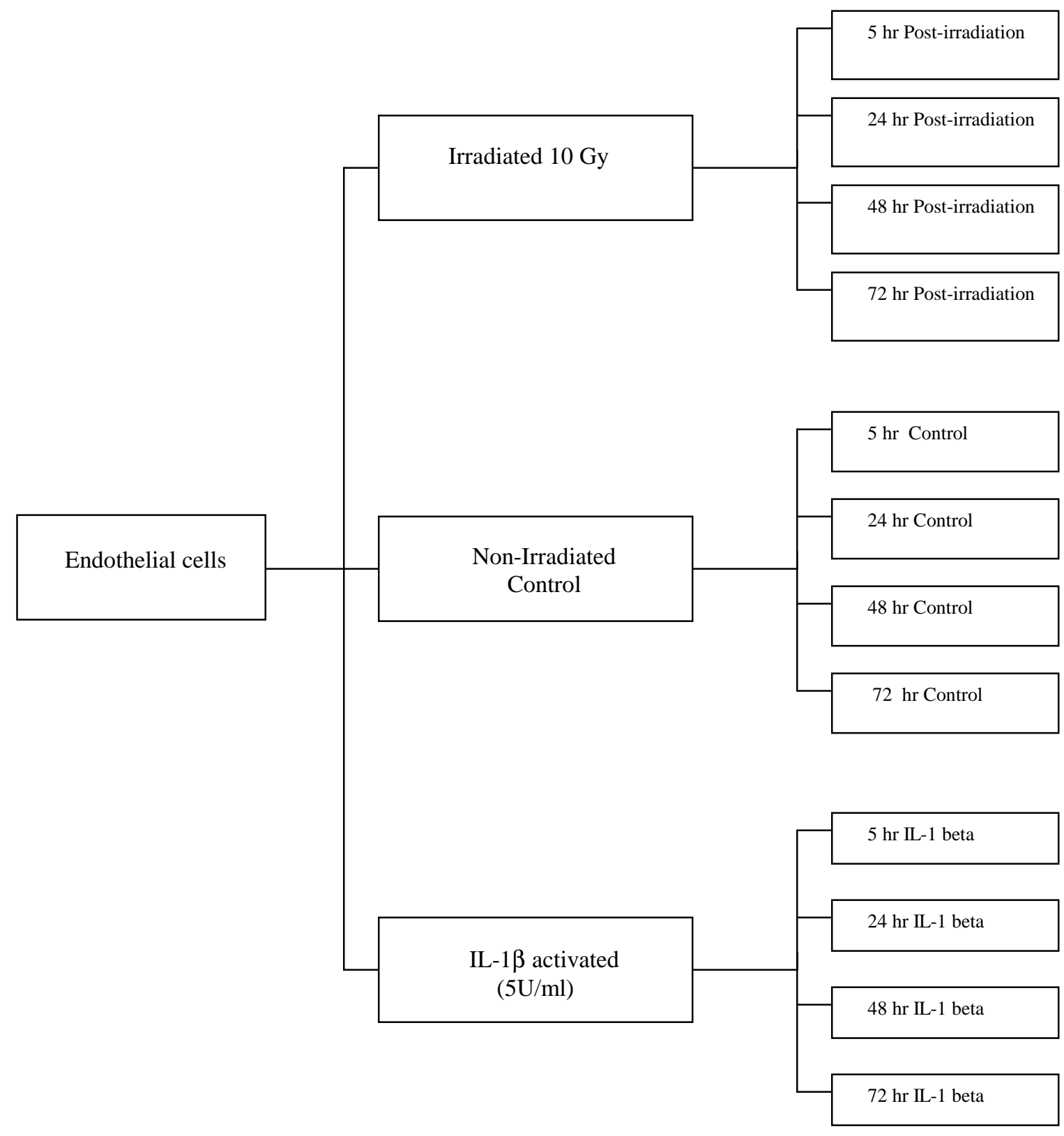

Figure 3-1. Experimental design of the study.

To study the functional interactions, human promyelocytic leukemia cells (HL60), which have become a standard for use as substitutes of leukocytes were utilized in an in vitro flow chamber to model the in vivo flow conditions. In vitro flow chambers provide the flexibility and 
control to vary the shear stress by varying the flow rates in order to understand the pathophysiological consequences following radiation.

\section{Media}

M199, RPMI-1640, Fetal bovine serum (FBS), L-glutamine, penicillin/streptomycin solution, EDTA-Trypsin solution, Trypsin neutralizing solution, and Dulbeco phosphate buffer solution (DPBS) was obtained from Biowhittaker, Walkersville, MD. MCDB131 was purchased from Life Technologies, Rockville, MD. Endothelial growth factor was bought from Biomedical Technologies, Boston, MA. Gelatin, heparin, dibutyryl cyclic AMP, Formaldehyde and hydrocortisone were obtained from Sigma Chemical, St. Louis, MO. Bovine serum albumin was obtained from Fisher Scientific, Pittsburgh, PA.

\section{Antibodies and Cytokines}

IL-1 $\beta$ was obtained from Calbiochem, La Jolla, CA. Antibodies to E-selectin, ICAM-1 and IgG1 were obtained from R \& D systems, Minneapolis, MN. Anti-mouse IgG, Heavy and Light Chain(Goat) F ( $\left.\mathrm{ab}^{\prime}\right)_{2}$ fragment conjugated to FITC was purchased from Caltag Laboratories, CA. Antibodies to LFA-1, PSGL-1, Sle ${ }^{\mathrm{x}}, \beta_{2}$ integrin and Mac-1 were kind gifts of Dr. Douglas Goetz of University of Memphis, TN.

\section{Endothelial Cell Cultures}

Human umbilical vein endothelial cells (HUVECs) were obtained from Birthing Center, Strong Memorial Hospital, Rochester, NY). Human microvascular endothelial cells (HDMECs) 
and transformed human microvascular endothelial cells (HMEC-1) were obtained from Dr. Robert Swerlick, Emory University, Atlanta, GA.

Human umbilical cord veins were utilized as a source of endothelial cells (HUVEC) utilizing the methods of Gimbrone et al. (33)and Wagner et al. (78) as modified by Sporn et al. (71). A sterile technique was employed in all manipulations of the cord. The cord was severed from the placenta soon after birth, placed in a sterile container and held at $4^{\circ} \mathrm{C}$ until processing. Storage time did not exceed 48 hours. The cells were allowed to grow for 72-96 hours and were then passaged in $\mathrm{T} 25 \mathrm{~cm}^{2}$ culture flasks pre-coated with $0.2 \%$ gelatin for use in our studies. All umbilical cords used were considered normal by the obstetrical staff (Birthing Center, Strong Memorial Hospital, Rochester, NY). Cells were maintained in M199 with 10 \% FBS, 2mM Lglutamine supplemented with $100 \mu \mathrm{g} / \mathrm{ml}$ of heparin, $50 \mu \mathrm{g} / \mathrm{ml}$ of endothelial growth factor and $100 \mathrm{U} / \mathrm{ml}$ penicillin/streptomycin on $0.2 \%$ gelatin coated tissue culture dishes at $37^{\circ}$ in $5 \% \mathrm{CO}_{2}$. Confluent cells were trypsinized and subcultured at a ratio of 1:3. All the studies were conducted on passage 3-6 of these cells.

Transformed microvascular endothelial cells were maintained in MCDB131 with10 \% FBS, 2mM L-glutamine and 100U/ml penicillin/streptomycin solution on $0.2 \%$ gelatin coated tissue culture dishes at $37^{\circ}$ in $5 \% \mathrm{CO}_{2}$. Confluent cells were trypsinized and subcultured at a ratio of 1:3. Cells used in our studies were from passage 22-26.

Primary microvascular endothelial cells were isolated from human neonatal foreskins as described previously (75) and were obtained from the laboratories of Dr. Robert Swerlick at the Emory University. Culture medium was MCDB131 with 10\% human serum (Irvine Scientific), 10\% FBS, 2mM L-glutamine, 5 x10-4 M dibutyryl cyclic AMP, $1 \mu \mathrm{g} / \mathrm{ml}$ hydrocortisone acetate and $100 \mathrm{U} / \mathrm{ml}$ of penicillin/streptomycin. The cells were grown on $0.2 \%$ gelatin coated tissue 
culture dishes at $37^{\circ}$ in $5 \% \mathrm{CO}_{2}$. Confluent cells were trypsinized and subcultured at a ratio of 1:3. Cells used in our studies were from passage 4-7.

\section{HL60 Cells}

HL60 (human promyelocytic leukemia cells) were obtained from American Type Cell Culture (ATCC, Manassas, VA). The frozen cells were thawed at $37{ }^{\circ} \mathrm{C}$ and placed in RMPI1640 media supplemented with 10\% FBS, 2mM L-glutamine and $100 \mathrm{U} / \mathrm{ml}$ of penicillin/streptomycin in a $775 \mathrm{~cm}^{2}$ flask. The flask was incubated at $37^{\circ} \mathrm{C}$ in $5 \% \mathrm{CO}_{2} . \mathrm{HL60}$ cells grow in suspensions. Upon reaching confluence, the cell suspension was further diluted to allow for more cell growth.

\section{Irradiation}

Prior to irradiation, confluent endothelial cells in $\mathrm{T} 25 \mathrm{~cm}^{2}$ flasks were replenished with fresh media. HDMECs media was replaced with media lacking cyclic AMP (cyclic AMP has been found to suppress expression of E-selectin $(60,66)$. Cells were irradiated with a single dose of radiation (10 Gy (X-ray or gamma)). The x-ray dose rate was 2 Gy/min using a Siemens Primus (4000 series) linear accelerator $(6 \mathrm{MV})$ and the collimator diameter used was $5 \mathrm{~cm}$. The dose calculations and calibrations were performed by Dr. Waleed Gaber (Research Investigator at the St. Jude Children's Hospital, Memphis, TN). The gamma radiation was delivered from Mark I, cesium source irradiator (Veterans Affair Hospital, Memphis, TN) at a dose rate of 4.2 Gy per minute. Cells taken to the radiation facility but not irradiated served as negative controls. IL-1 $\beta(10 \mathrm{U} / \mathrm{ml})$ activated cells served as positive controls to show the presence of the adhesion 
molecules. Post-irradiation cells were incubated at $37^{\circ} \mathrm{C}$ for $5 \mathrm{hr}, 24 \mathrm{hr}, 48 \mathrm{hr}$ and $72 \mathrm{hr}$ to be analyzed for the expression of adhesion molecules.

For the in vitro flow assay, endothelial cells were grown in $35 \mathrm{~mm}$ dishes. Confluent cells were irradiated and incubated until the experimental time points. Non-irradiated cells served as negative controls and IL-1 $\beta$ activated cells served as positive controls.

\section{Flow Cytometry}

Flow cytometric analysis was carried out to test for the presence of adhesion molecules. At the respective time points post-IR ( $5 \mathrm{hr}, 24 \mathrm{hr}, 48 \mathrm{hr}$ and $72 \mathrm{hr}$ ), cells were trypsinized with $0.01 \%$ EDTA-trypsin mixture in the presence of $1 \%$ BSA. Cells were washed in phosphate buffer saline and incubated with antibodies to E-selectin, ICAM-1 or murine IgG1 at a concentration of $20 \mu \mathrm{g} / \mathrm{ml}$ for 30 minutes at $4^{\circ} \mathrm{C}$. Cells were washed and incubated with secondary antibody (Anti-mouse IgG, Heavy and Light Chain(Goat) F (ab') 2 fragment conjugated to FITC for further 30 minutes at $4{ }^{\circ} \mathrm{C}$ (1:50 neat dilution of antibody). Cells were washed and fixed in $2 \%$ formaldehyde to be analyzed using flow cytometry (Epics - Profile II Beckman Coulter Inc., Fullerton, CA).

Flow cytometric analysis was also carried on the HL60 cells to check for the expression of ligands of the adhesion molecules E-selectin and ICAM-1; namely, Sle ${ }^{\mathrm{x}}$, PSGL-1, LFA-1, Mac-1, and the $\beta_{2}$ integrin chain. In brief, HL60 cell suspension was placed in a $50 \mathrm{ml}$ centrifuge tube and was centrifuged at $12,000 \mathrm{rpm}$ for 5 minutes at $37^{\circ} \mathrm{C}$. The cells were washed in RPMI -1640 media containing 5\% FBS and resuspended to $1 \times 10^{6}$ cells $/ \mathrm{ml}$. One $\mathrm{ml}$ of the suspension was aliquoted into $1.5 \mathrm{ml}$ centrifuge tubes. The cells were spun down and $40 \mu \mathrm{l}$ of antibody $(20 \mu \mathrm{g} / \mathrm{ml})$ diluted in RPMI-1640 was added against Sle ${ }^{\mathrm{x}}$, PSGL-1, LFA-1, Mac-1, and the $\beta_{2}$ 
integrin chain and incubated at $4{ }^{\circ} \mathrm{C}$ for 30 minutes. The cells were washed and incubated for further 30 minutes at $4{ }^{\circ} \mathrm{C}$ with secondary antibody (Anti-mouse IgG, Heavy and Light Chain (Goat) $\mathrm{F}(\mathrm{ab})_{2}$ fragment ) conjugated to FITC at 1:50 neat dilution. The cells were washed with RMPI-1640 and then fixed in 2\% DPBS to be analyzed in a flow cytometer (Epics - Profile II Beckman Coulter Inc., Fullerton, CA).

\section{In Vitro Flow Chamber Assay}

To probe the functional consequence of the presence of adhesion molecules on the irradiated endothelium a flow assay was used. The flow chamber was obtained from Glycotech (Rockville, MD). A schematic of the flow chamber is shown in Figure 3-2.

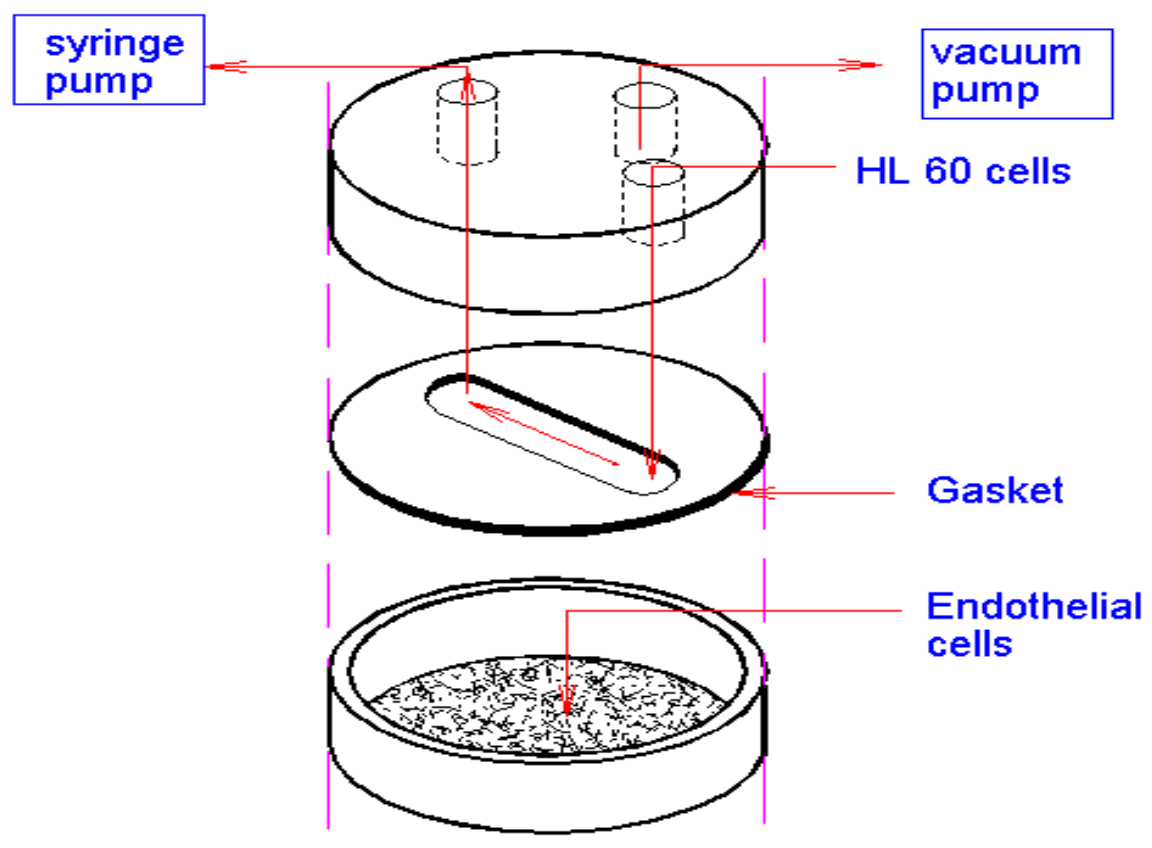

Figure 3-2. Schematic of the flow chamber. 
The irradiated cells on the $35 \mathrm{~mm}$ dish were washed with the HL60 cells media (RPM1 1640 with $10 \%$ FBS and $100 \mathrm{U} / \mathrm{ml}$ of Penicillin/Streptomycin) and the flow chamber was placed over it. A gasket of approximate thickness $250 \mu \mathrm{m}$ was placed between the culture dish and the flow chamber (the exact thickness of the gasket was obtained with the use of the $\mathrm{z}$ axis scale on the microscope). The flow path width was $0.5 \mathrm{~cm}$. The flow chamber was placed over an inverted microscope (Nikon, Japan-TE300 series) and viewed at 10x Phase1. HL60 cells (10 5 cells/ml) suspended in RPM1-1640 media were perfused over the endothelial cells at shear stress values of $0.5-2.0$ dynes $/ \mathrm{cm}^{2}$ by varying the flow rate with a syringe pump (Harvard Apparatus, Boston, MA). These shear stress are values are typically observed in the post-capillary venules in vivo (70).

The flow rate needed to develop the desired shear stress was calculated using the equation for the shear stress at the wall in a parallel plate flow chamber:

$$
\gamma=\frac{3 \mu \mathrm{Q}}{2 \mathrm{~h}^{2} \mathrm{~W}}
$$

where $\gamma=$ shear stress in dynes $/ \mathrm{cm}^{2}$

$$
\begin{aligned}
& \mu=\text { viscosity of the medium }(0.76 \mathrm{cP} \text { in our experiments }) \\
& \mathrm{Q}=\text { flow rate of the medium containing HL60 cells }(\mathrm{ml} / \mathrm{min}) \\
& \mathrm{h}=\text { thickness of the gasket (height of the chamber }) \text { in } \mathrm{cm} \\
& \mathrm{w}=\text { flow path width }(0.5 \mathrm{~cm})
\end{aligned}
$$

The derivation for equation 1 has been shown previously (70). Experiments were recorded with a video camera (Dage-MTI, Inc, USA). The number of rolling, and adherent cells were counted for a period of 3 minutes. The camera was connected to a video monitor (Panasonic Model No. WV-5410) and the images were recorder on SVHS videotapes on a video 
recorder (JVC SVHS Model No. HR-54900U) for offline analysis. A video title maker (Videonics Title Maker 3000, Mexico) was used to place an electronic time and stamp (containing experimental date, radiation status, lens used and the shear stress) on each video field. The experimental set up is shown in Figure 3-3.

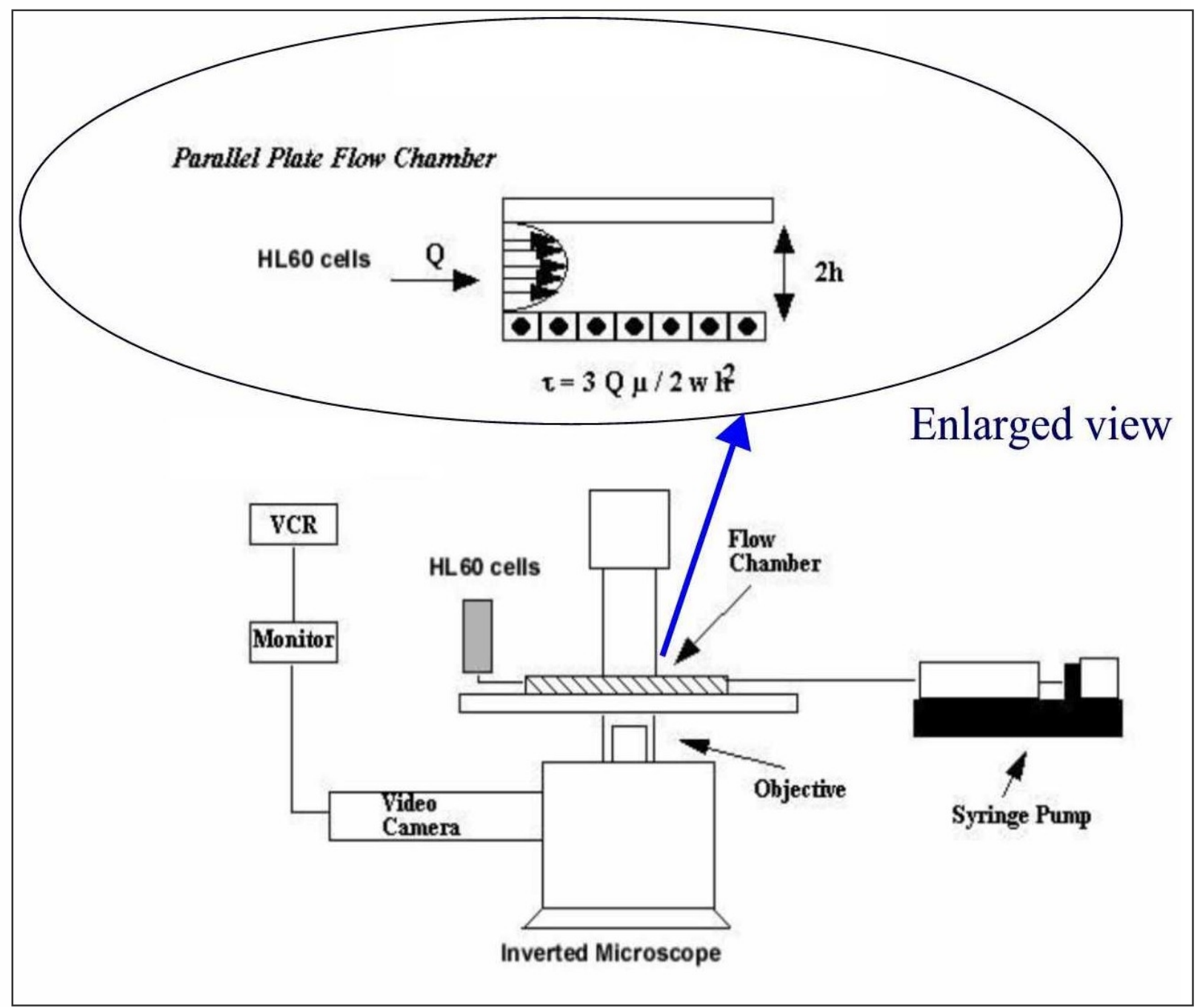

Figure 3-3. Experimental setup of the flow chamber assay.

A semi-static flow assay was used at $48 \mathrm{hr}$ post-irradiation to investigate the functional significance of the upregulation of ICAM-1 (semi-static assay was used as ICAM-1 binds to its ligands only under static conditions). Semi-static adhesion assays were performed by 
introducing HL60 cells into the flow chamber (shear stress of 0.5 and 1.0 dynes $/ \mathrm{cm}^{2}$ ), stopping the flow, incubating for 15 minutes allowing the HL60 cells to adhere to the endothelium, and reintroducing the flow at shear stress of 0.5 and 1.0 dynes $/ \mathrm{cm}^{2}$.

\section{Statistical Analysis}

One way analysis of variance (ANOVA) was used to detect significant differences among the groups (control, irradiated and IL-1 $\beta$ activated control) for the upregulation of adhesion molecules. A two-way analysis of variance was performed to detect significant changes with respect to time $(5,24,48$ and $72 \mathrm{hr})$, and radiation dose (5 and $10 \mathrm{~Gy})$. ANOVA was performed using SIGMASTAT software. A multiple comparison method (Fisher's least significant difference, LSD) was used to discriminate between the means. Differences between the mean were considered statistically significant if $\mathrm{P}<0.05$. 


\section{Chapter 4. RESULTS}

Expression of adhesion molecules following was quantified using flow cytometry at $5 \mathrm{hr}$, $24 \mathrm{hr}, 48 \mathrm{hr}$ and $72 \mathrm{hr}$ post-irradiation (10 Gy) on endothelial cells obtained from large vessels (HUVECs) and microvessels (HDMECs and HMEC-1). All the data for irradiated endothelial cells corresponds to a dose of 10 Gy unless stated otherwise. Statistically significant differences were observed for the expression of E-selectin only on HDMECs (control vs. irradiated). Statistically significant different levels of ICAM-1 were observed on all three endothelial cell types: HUVECs, HMEC-1 and HDMECs post-irradiation. The functional consequence of the presence of adhesion molecules was investigated using an in vitro flow chamber at shear stress values of 0.5-2.0 dynes $/ \mathrm{cm}^{2}$ at $5 \mathrm{hr}, 24 \mathrm{hr}$ and $48 \mathrm{hr}$ post-irradiation. Significant differences were found for HDMECs (control vs. irradiated) and HUVECs (control vs. irradiated).

The data are presented as Mean \pm SEM (Standard Error of the Mean), where * represents $(\mathrm{P}<0.05)$ and $* *$ represents $(\mathrm{P}<0.01)$. In order to investigate the controversial results regarding the upregulation of adhesion molecules depending on the radiation source (x-ray or gamma), we compared the expression of adhesion molecules following x-ray and gamma radiation.

Multifactor analysis of variance (ANOVA) was used to examine the effects of the two factors (time and radiation type) and their interactions on the expression of the adhesion molecules. We did not find significant differences $(\mathrm{P}>0.05)$ in the upregulation of adhesion molecules based on the radiation source (for example, Figure 4-1 shows the expression of ICAM-1 post-irradiation based on the radiation source). Hence the data from the $\mathrm{x}$-ray or gamma sources were pooled together to increase the statistical power. 


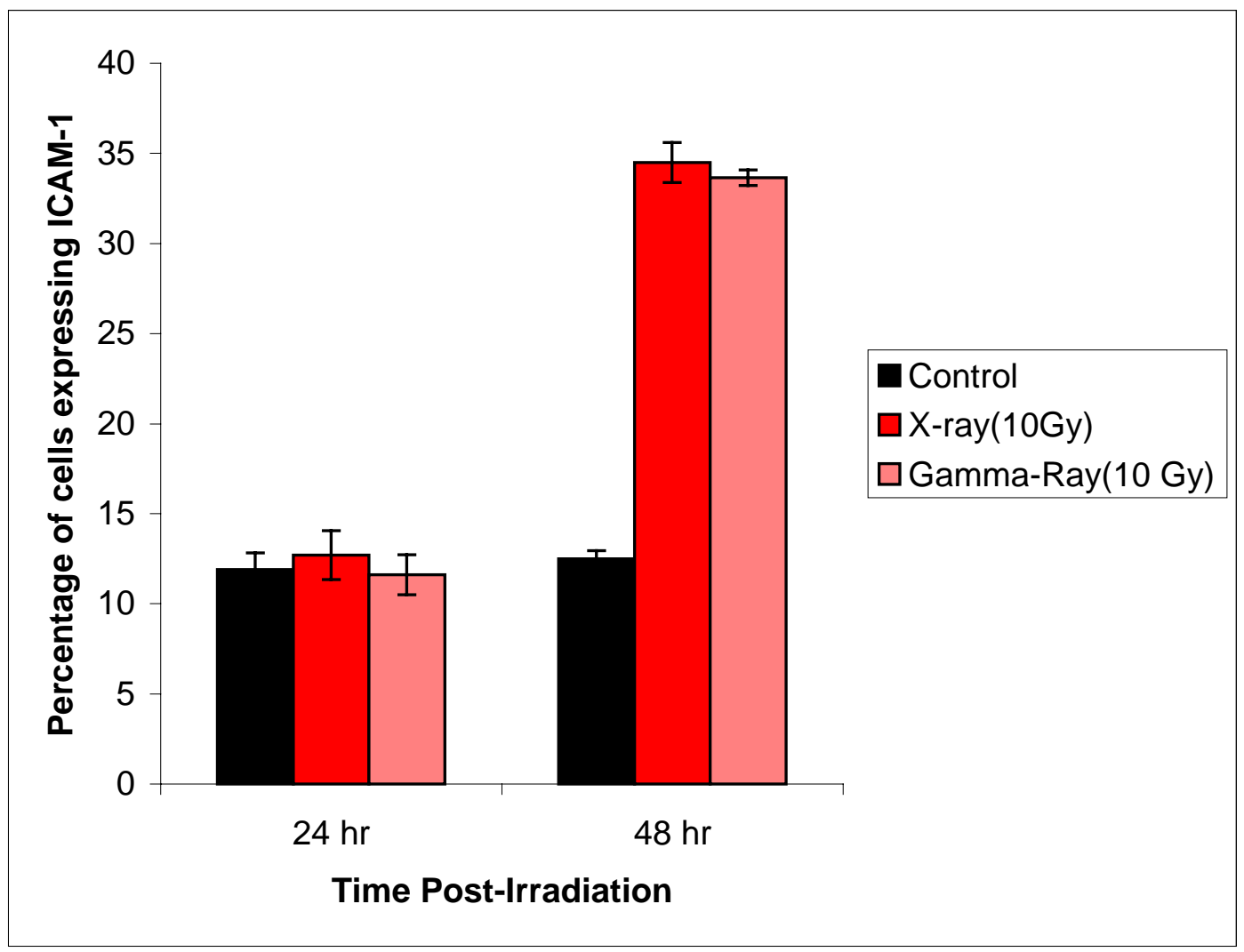

Figure 4-1. Comparison of expression of ICAM-1 on HUVECs using x-ray or gamma-radiation. $\mathrm{N}=6$ for all groups, $\mathrm{P}>0.05$ ( $\mathrm{x}$-ray vs. gamma)

\section{Morphology of Endothelial Cells Following Irradiation}

Endothelial cells started to become elongated and irregular in shape by $48 \mathrm{hr}$ post-

irradiation and started to lose contact with the adjacent cells (Figure 4-2b) leaving gaps in the monolayer. By $72 \mathrm{hr}$ post-irradiation, more endothelial cells started to peel off leaving prominent visible gaps in the monolayer of cells. IL-1 $\beta$ activated cells also became elongated by 48 hr postirradiation (Figure 4-2c), but maintained their contacts with adjacent endothelial cells at $48 \mathrm{hr}$ and $72 \mathrm{hr}$ post-irradiation. Control cells, however, retained their normal shape at all the time points and maintained uniform contact with the adjacent cells (Figure 4-2a). 


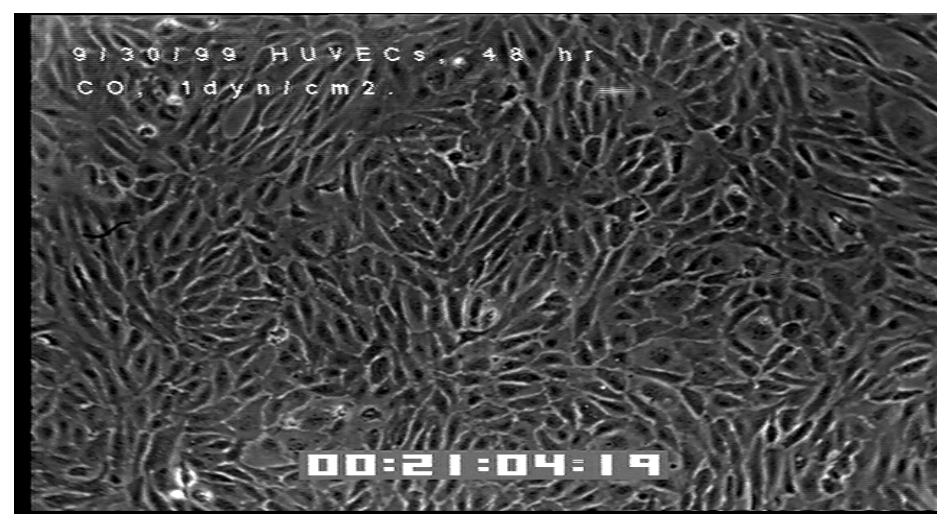

(a)

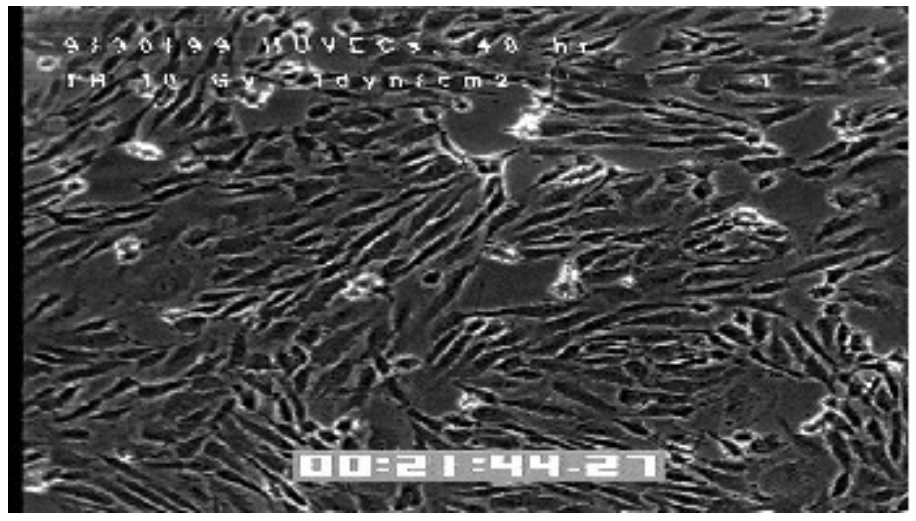

(b)

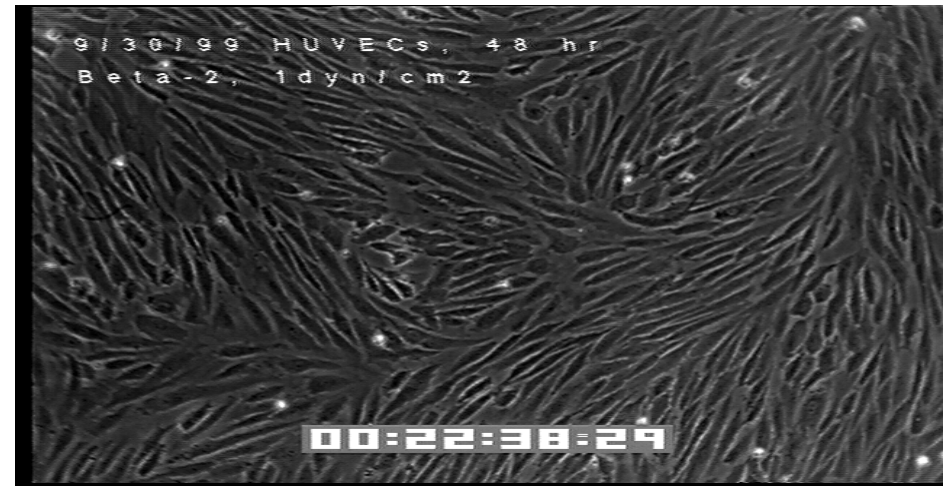

(c)

Figure 4-2. Morphology of endothelial cells following activation and irradiation. (a). Non-IR HUVECs, (b). $48 \mathrm{hr}$ post-IR HUVECs, (c). $48 \mathrm{hr}$ post-IL-1 $\beta$ activated HUVECs 


\section{Expression of E-selectin on Endothelial Cells}

E-selectin expression was analyzed at $5 \mathrm{hr}, 24 \mathrm{hr}$ and $48 \mathrm{hr}$ post-irradiation using flow cytometry on HUVECs, and HMEC-1. Experiments were conducted on HDMECs only at $5 \mathrm{hr}$ post-irradiation. $72 \mathrm{hr}$ time point post-irradiation was not considered because E-selectin expression by endothelial cells following activation by an inflammatory substance has been found to peak at 4-6 hr post-activation and returning to baseline values by $48 \mathrm{hr}$ (9) postactivation. Non-irradiated cells served as negative controls and IL-1 $\beta$ activated cells served as positive controls.

\section{Expression of E-selectin on HUVECs:}

HUVECs were used at passage 3-5 for these studies. These passage allow for uniform expression of the adhesion molecules by the endothelial cells. Flow cytometric analysis showed that HUVECs did not have a base line expression of E-selectin (Figure 4-3a). E-selectin upregulation was also not observed at $5 \mathrm{hr}$ (Figure 4-3b), $24 \mathrm{hr}$ (Figure 4-4) and $48 \mathrm{hr}$ postirradiation (Figure 4-4).

However, E-selectin was upregulated by $\mathrm{IL}-1 \beta$ and peaked at $5 \mathrm{hr}$ post-activation. There was a significant increase in the mean fluorescence intensity (Figure 4-3c) and in the number of cells expressing E-selectin. Almost 60-65 \% of the cells were expressing E-selectin at this time point (Figure 4-4) post activation. The percentage of cells expressing E-selectin and the mean fluorescence intensity decreased at $24 \mathrm{hr}$ post-activation by IL-1 $\beta$ and returned to almost baseline levels by $48 \mathrm{hr}$ post-activation. Figure $4-4$ provides a summary of the data for the expression of E-selectin on HUVECs. 


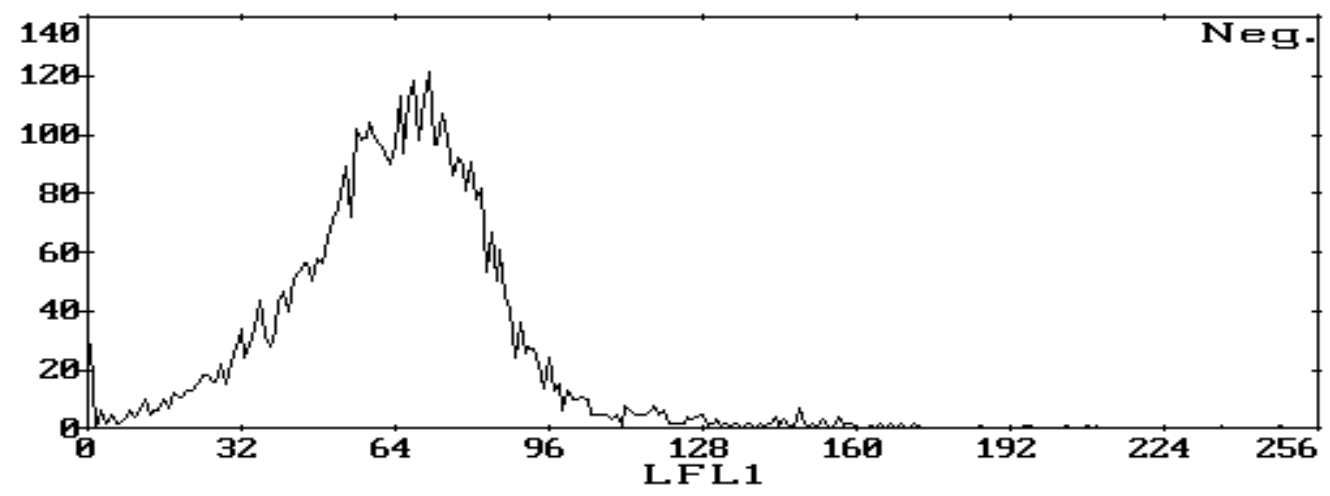

(a)

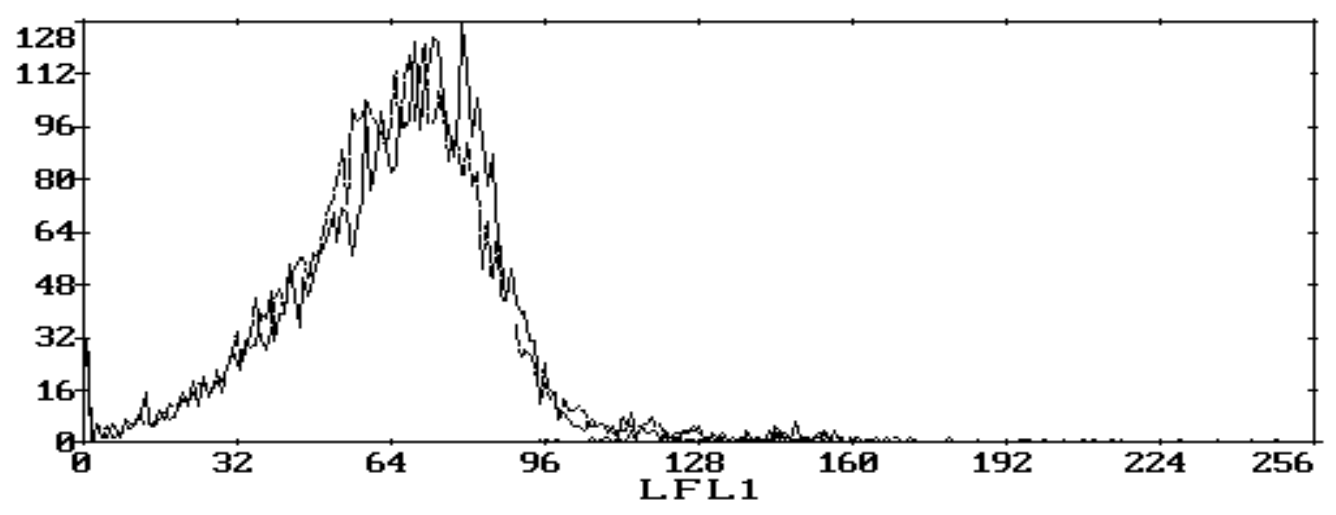

(b)

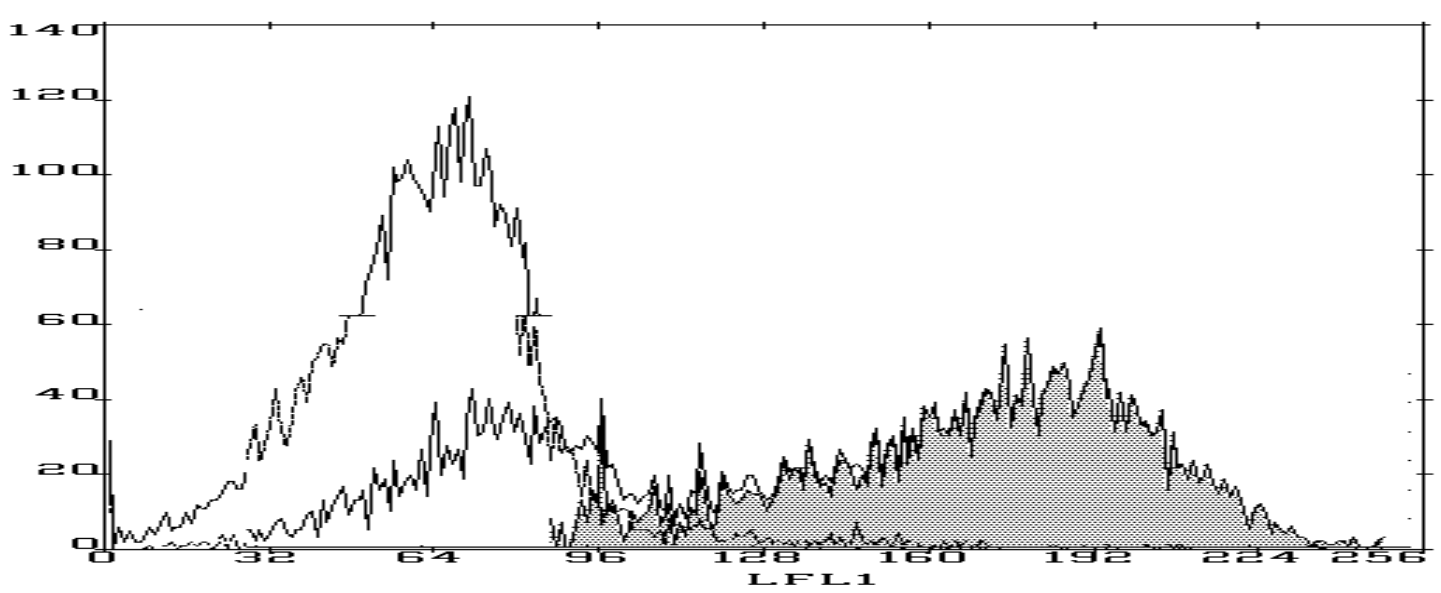

(c)

Figure 4.3. Flow cytometry plots showing expression of E-selectin on HUVECs.

(a). Non-IR (Control), (b). $5 \mathrm{hr}$ post-IR (10 Gy), (c). $5 \mathrm{hr}$ post-IL-1 $\beta$ activated 


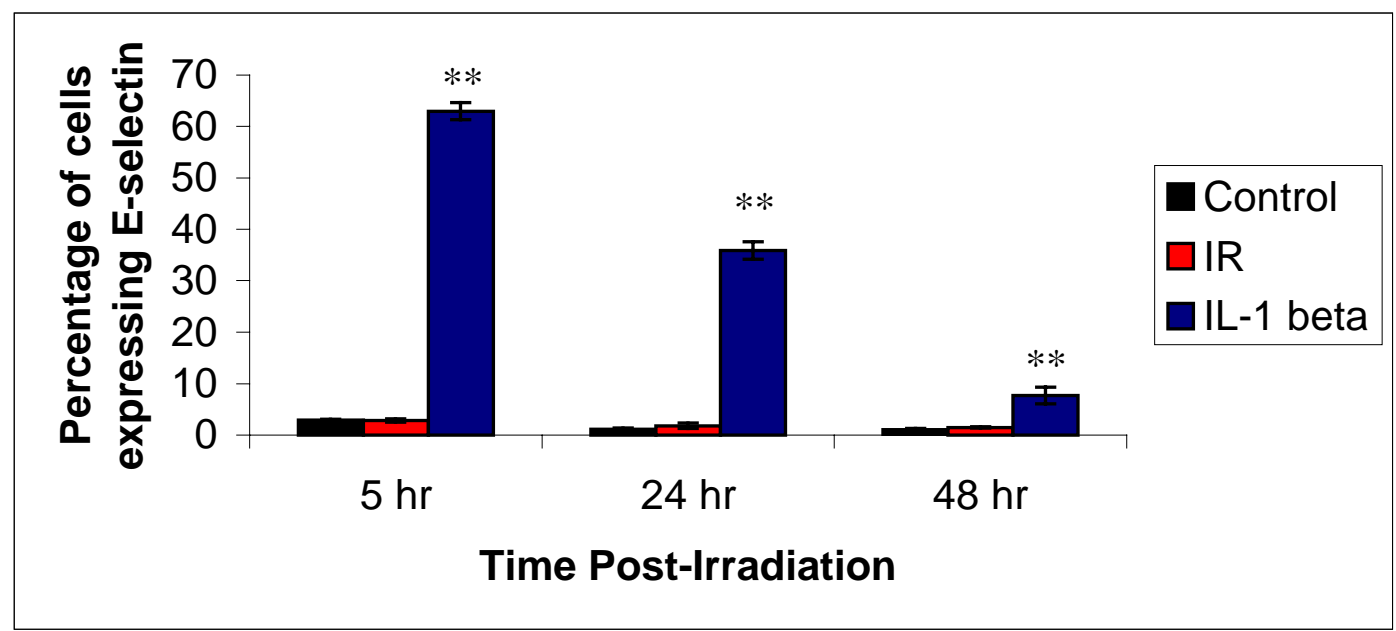

Figure 4-4. Expression of E-selectin post-IR (10 Gy) on HUVECs. $\mathrm{N}=3$ for all groups, Mean \pm SEM, $\mathrm{P}<0.01$ (for IL-1 beta vs. control)

\section{Expression of E-selectin on HMEC-1:}

HMEC-1 used in this study were passaged from 22-26. HMEC-1 did not possess a basal level of E-selectin expression. E-selectin expression was not upregulated by ionizing radiation (Figure 4-5). Interestingly, IL-1 $\beta$ failed to induce the expression of E-selectin in HMEC-1 (Figure 4-5).

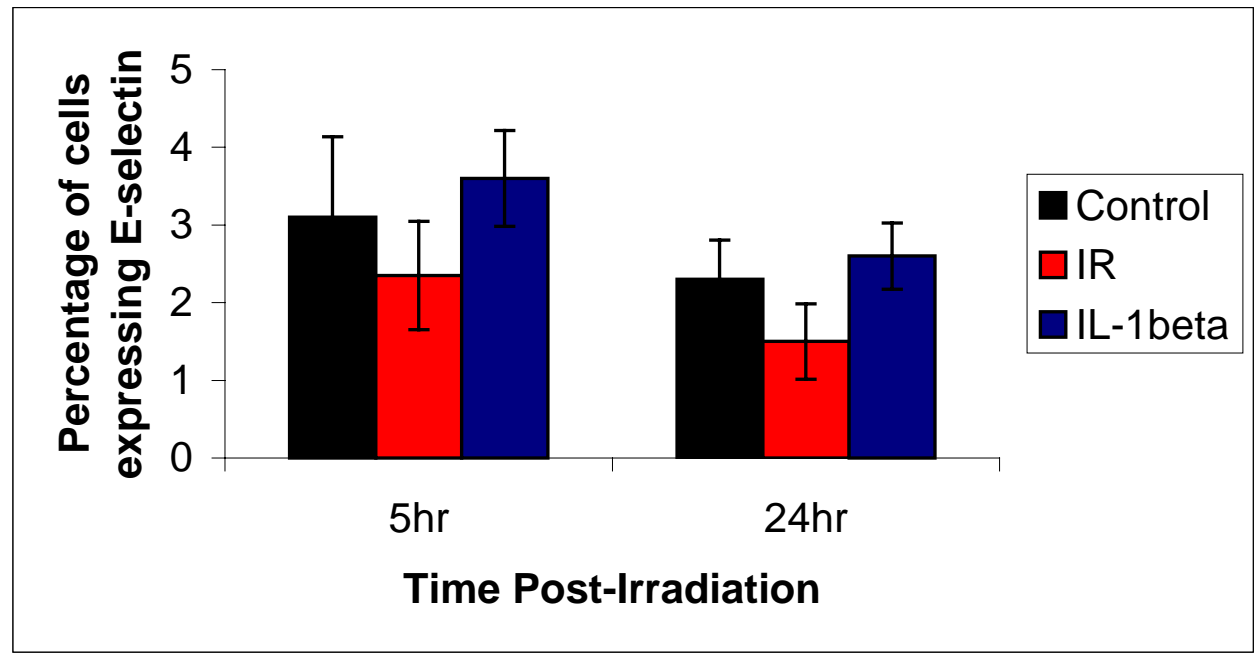

Figure 4-5. Expression of E-selectin post-IR (10 Gy) on HMEC-1. $\mathrm{N}=3$ for all groups, Mean $\pm \mathrm{SEM}, \mathrm{P}>0.05$ 


\section{Expression of E-selectin on HDMEC:}

HDMEC cells used for this study were at passage 3-6. Surprisingly, flow cytometric analysis indicated that HDMECs have a basal level of E-selectin expression (Figure 4-6). Approximately $7 \%$ of the cells were expressing E-selectin under control conditions. E-selectin was upregulated $5 \mathrm{hr}$ post-irradiation on HDMECs (Figure 4-6).

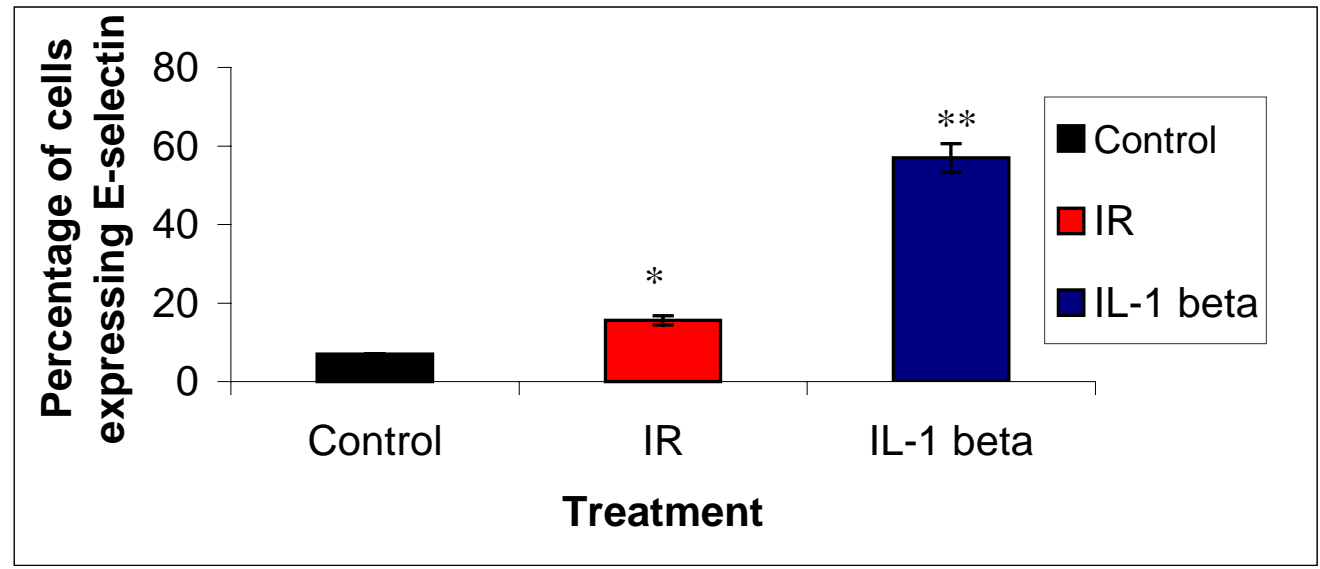

Figure 4-6. Expression of E-selectin on 5hr post-IR (10 Gy) HDMECs. $\mathrm{N}=3$, Mean \pm SEM, $\mathrm{P}<0.05$ (for control vs. IR), $\mathrm{P}<0.01$ (IL-1 beta vs. control)

\section{Expression of ICAM-1 on Endothelial Cells}

ICAM-1 expression was quantified at $5 \mathrm{hr}, 24 \mathrm{hr}, 48 \mathrm{hr}$ and $72 \mathrm{hr}$ post-irradiation.

\section{Expression of ICAM-1 on HUVECs:}

A flow cytometric plot of control HUVECs at $72 \mathrm{hr}$ is shown in Figure 4-7a. 10-15\% of the HUVECs had a basal level of ICAM-1, which increased to $25-30 \%$ by $72 \mathrm{hr}$ in non-irradiated controls. ICAM-1 was upregulated at $48 \mathrm{hr}$ post-irradiation and the level increased by $72 \mathrm{hr}$ (Figure 4-7b). IL-1 $\beta$ activated cells increased the expression of ICAM-1 by $5 \mathrm{hr}$, reaching a 
maximum level by $24 \mathrm{hr}$ which remained elevated at $72 \mathrm{hr}$ post-activation (see Figure 4-7c). The data is summarized in Figure 4-8.

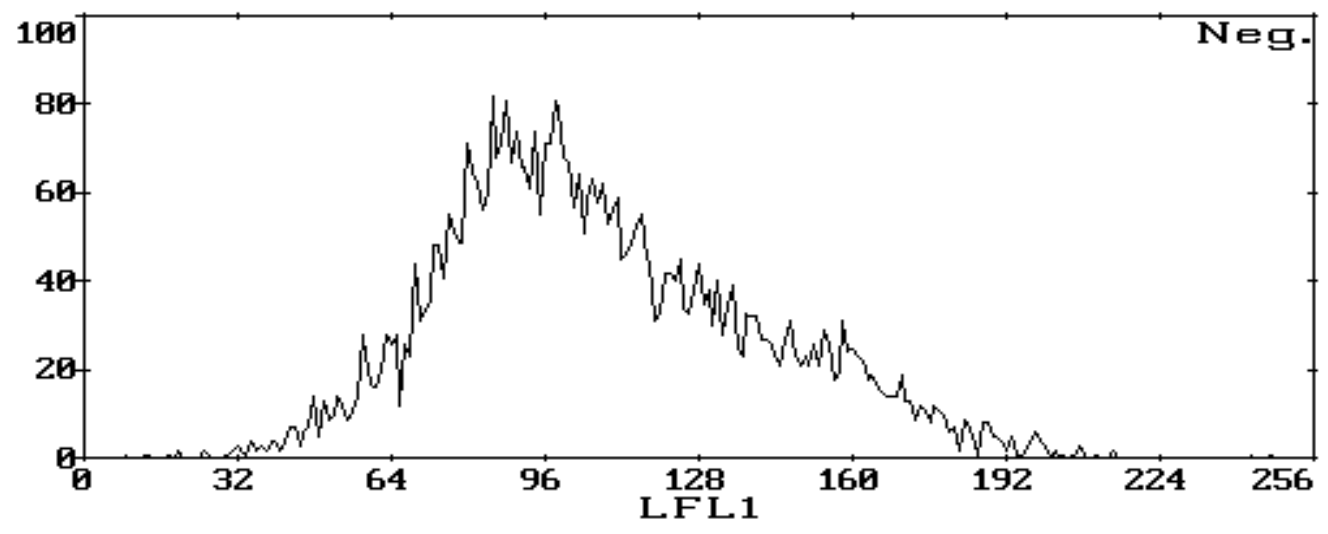

(a)

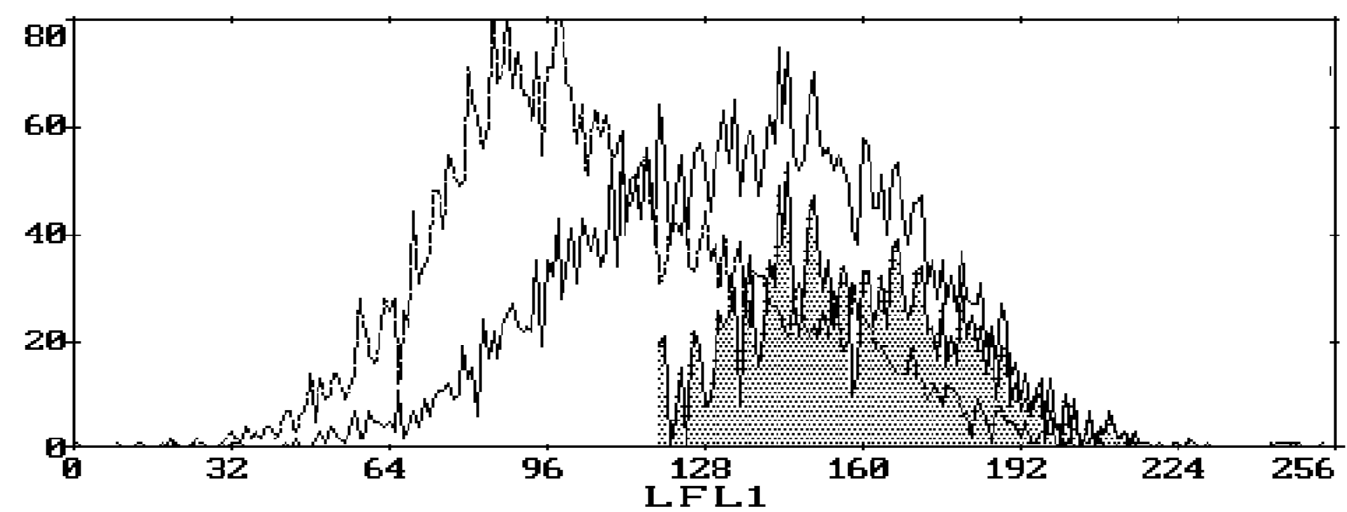

(b)

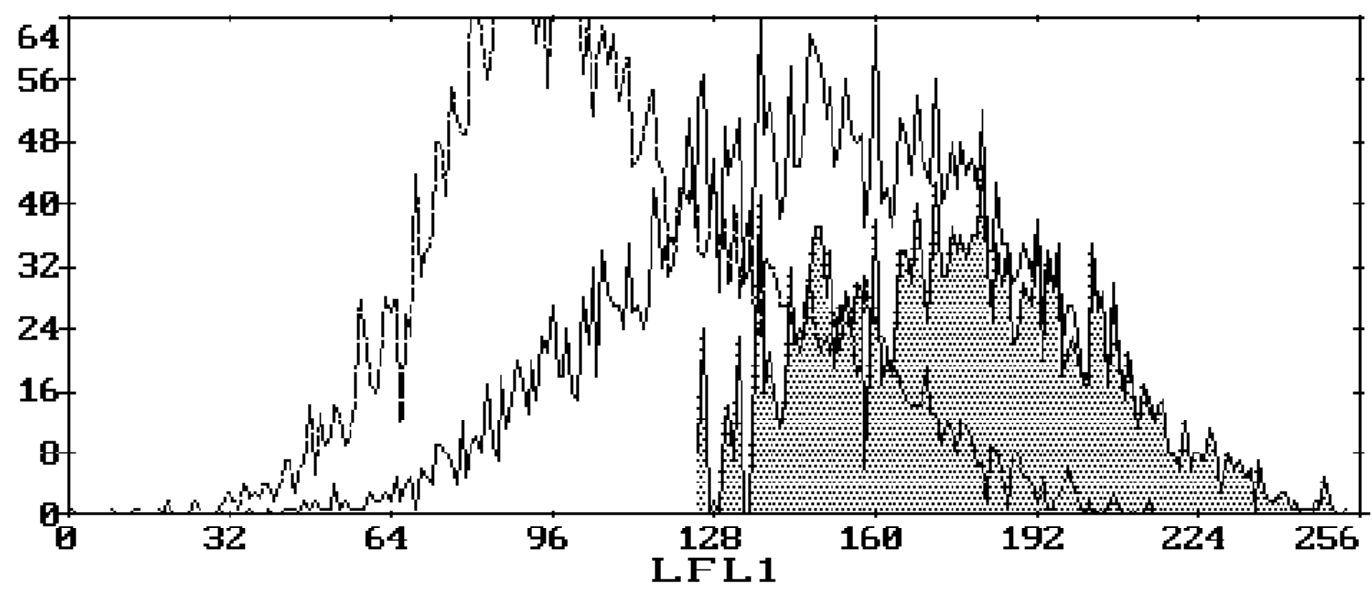

(c).

Figure 4-7. Flow cytometry plots showing expression of ICAM-1 on HUVECs. (a). Non-IR (Control), (b). $72 \mathrm{hr}$ post-IR (10 Gy), (c). $72 \mathrm{hr}$ post-IL-1 $\beta$ activated. 


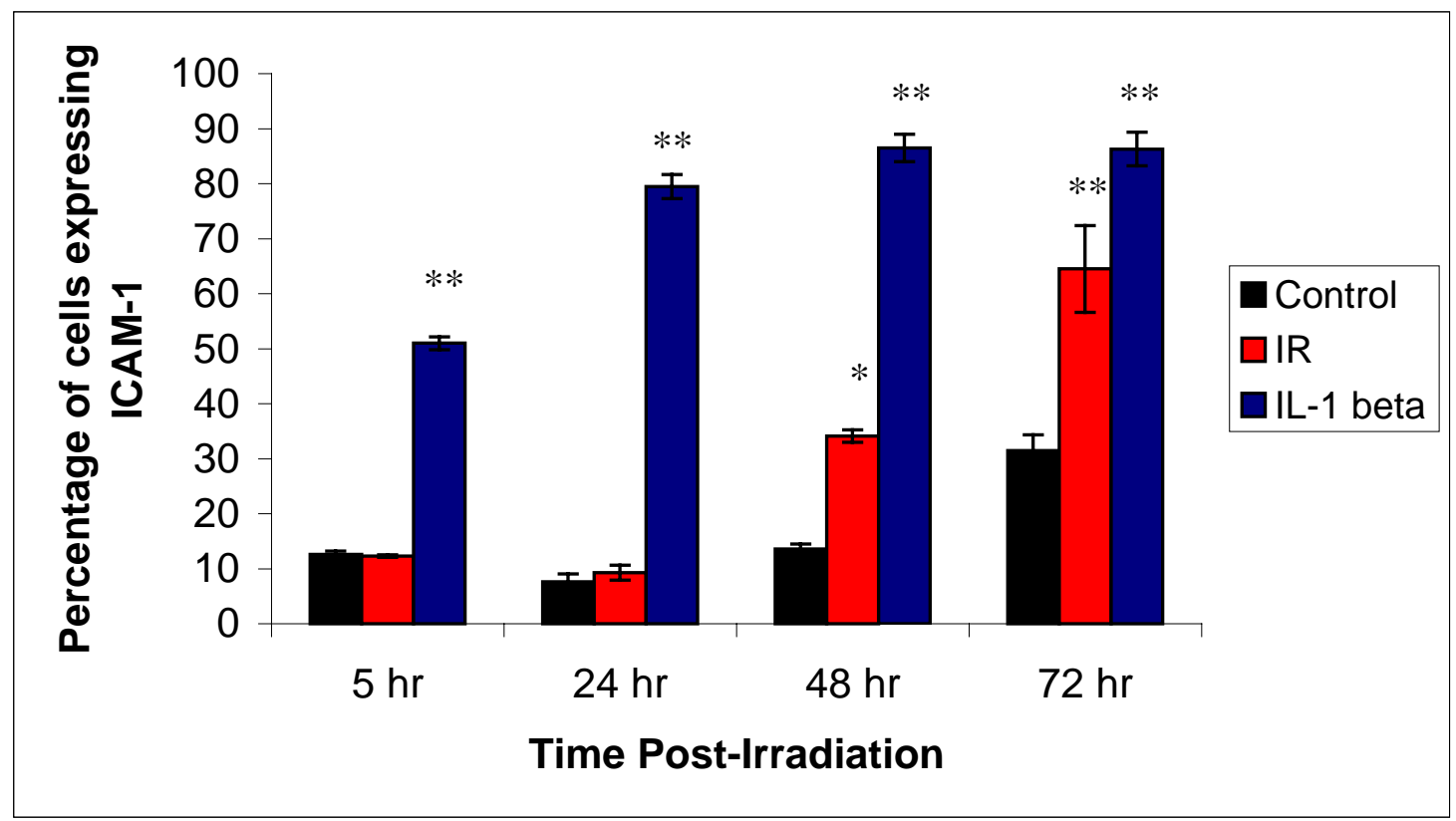

Figure 4-8. Expression of ICAM-1 on post-IR (10 Gy) HUVECs.

$\mathrm{N}=5$ for all groups, Mean \pm SEM, $\mathrm{P}<0.05$ (control vs. IR or IL-1 beta) and $\mathrm{P}<0.01$ (control vs. IR or IL-1 beta)

\section{Expression of ICAM-1 on HMEC-1:}

HMEC-1 were used at passages 21-26 for these series of experiments. HMEC-1 had a basal level of ICAM-1 expression similar to that observed on HUVECs (10-12\% of the cells expressed ICAM-1). ICAM-1 was upregulated at $48 \mathrm{hr}$ post-irradiation and the level increased significantly by $72 \mathrm{hr}$ post-irradiation (Figure 4-9). However, the level of ICAM-1 upregulation was only 1.5 times (control vs. irradiated) which was significantly less compared to the ICAM-1 level on HUVECs (2.4 fold increase on irradiated HUVECs compared to control). In addition, IL-1 $\beta$ activated cells expression of ICAM-1 was also significantly less (75\% of the cells expressed ICAM-1) than the corresponding levels of expression of ICAM-1 by HUVECs (90\% of the cells were expressing ICAM-1). 


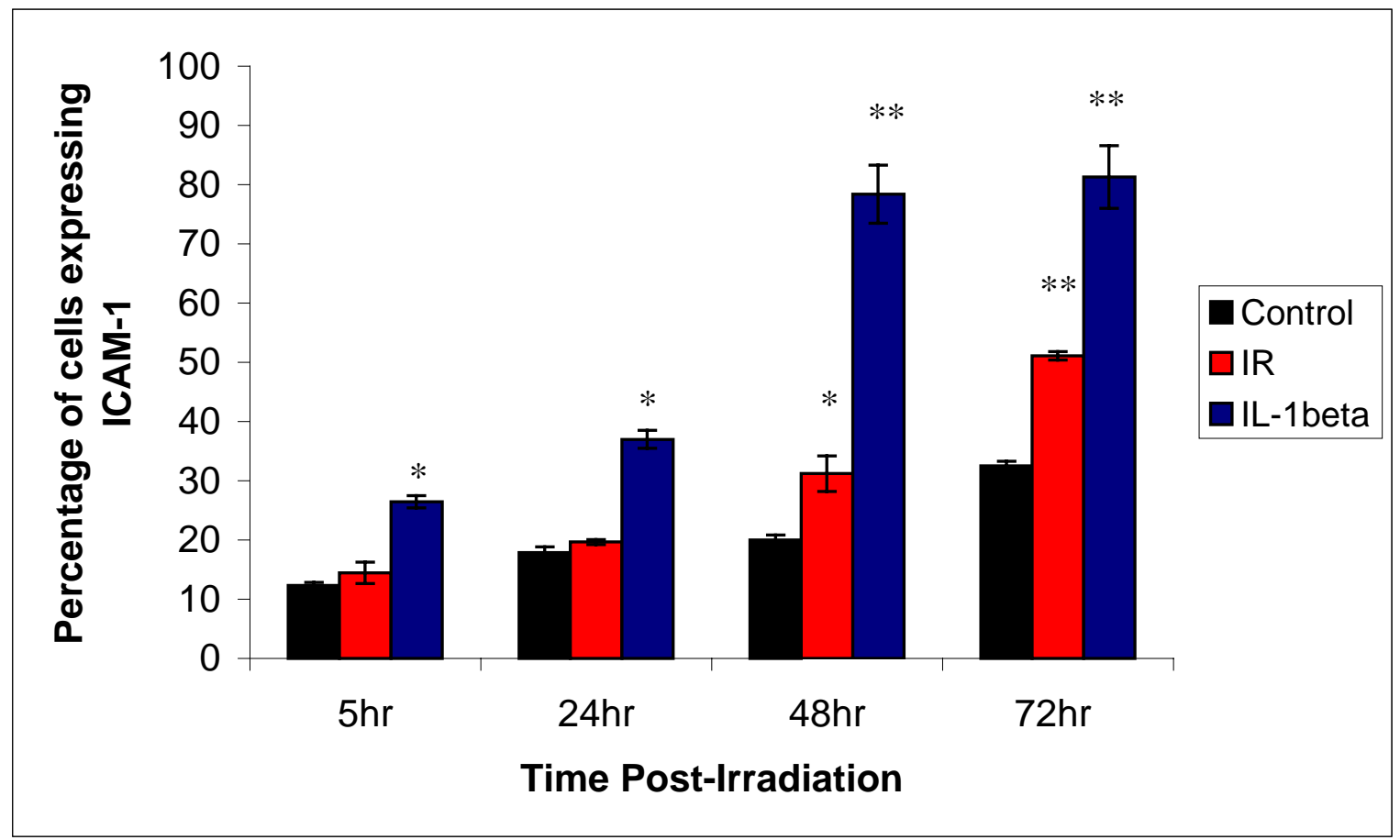

Figure 4-9. Expression of ICAM-1 on post-IR (10 Gy) HMEC-1.

$\mathrm{N}=3$ for all groups, Mean $\pm \mathrm{SEM}, \mathrm{P}<0.05$ (control vs. IR or IL-1 beta), $\mathrm{P}<0.01$ (control vs. IR or IL-1 beta)

\section{Expression of ICAM-1 on HDMECs:}

HDMECs had a significantly higher basal level of ICAM-1 compared to HMEC-1 and HUVECs. Almost 50-55\% of the cells expressed ICAM-1 (Figure 4-10). However, ICAM-1 was upregulated as early as $24 \mathrm{hr}$ post-irradiation and the level reached $90-95 \%$ by $48 \mathrm{~h}$ (Figure 4-10). $72 \mathrm{hr}$ time point was not included for these cells. On IL-1 $\beta$ activated cells, ICAM-1 expression peaked by $24 \mathrm{hr}$ reaching $95 \%$ expression levels and remained at the same elevated level at 48hr post-irradiation (Figure 4-10).

A summary of data representing the time and significant level of upregulation of adhesion molecules; E-selectin and ICAM-1 on the endothelial cells is presented in Table 4-1. 


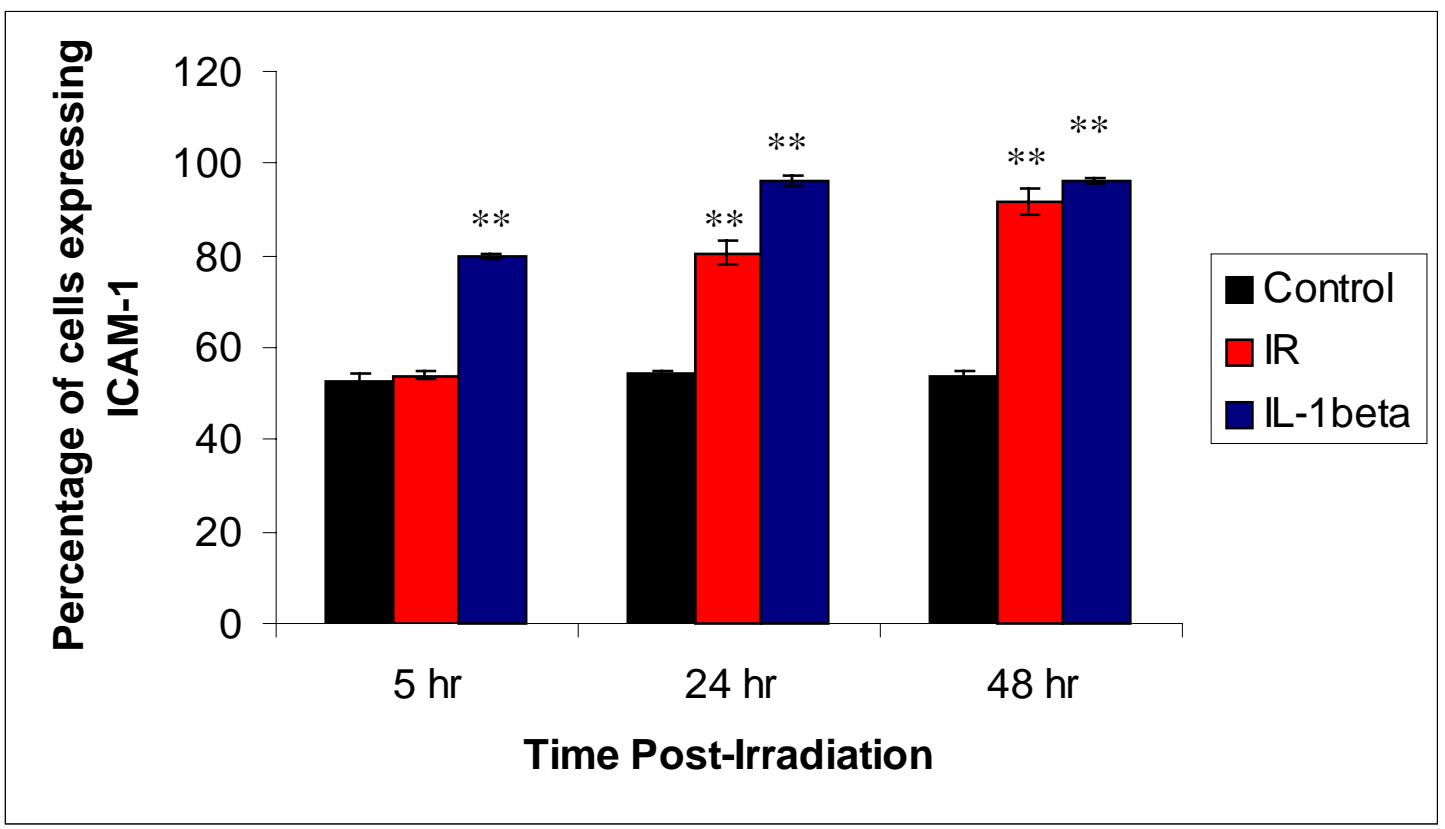

Figure 4-10. Expression of ICAM-1 on post-IR (10 Gy) HDMECs.

$\mathrm{N}=3$ for all groups, $\mathrm{P}<0.01$ (control vs. IR or IL-1 beta)

Table 4-1. Summary of the adhesion molecules being upregulated following irradiation.

\begin{tabular}{|c|c|c|c|c|c|c|}
\hline \multirow[t]{2}{*}{. Cell type } & \multirow[t]{2}{*}{ Molecules } & \multirow{2}{*}{$\begin{array}{c}\text { Baseline } \\
\text { Expression }\end{array}$} & \multicolumn{4}{|c|}{ Time Post-Irradiation (10 Gy) } \\
\hline & & & $5 \mathrm{hr}$ & $24 \mathrm{hr}$ & $48 \mathrm{hr}$ & $72 \mathrm{hr}$ \\
\hline \multirow{2}{*}{ HUVECs } & E-selectin & No & No & No & No & No \\
\hline & ICAM-1 & Yes & No & No & $\begin{array}{c}\text { Yes } \\
(\mathrm{P}<0.01)\end{array}$ & $\begin{array}{c}\text { Yes } \\
(\mathrm{P}<0.01)\end{array}$ \\
\hline \multirow{2}{*}{ HMEC-1 } & E-selectin & No & No & No & No & No \\
\hline & ICAM-1 & Yes & No & No & $\begin{array}{c}\text { Yes } \\
(\mathrm{P}<0.05)\end{array}$ & $\begin{array}{c}\text { Yes } \\
(\mathrm{P}<0.01)\end{array}$ \\
\hline \multirow[t]{2}{*}{ HDMECs } & E-selectin & Yes & $\begin{array}{c}\text { Yes } \\
(\mathrm{P}<0.05)\end{array}$ & NA & NA & NA \\
\hline & ICAM-1 & Yes & No & $\begin{array}{c}\text { Yes } \\
(\mathrm{P}<0.01)\end{array}$ & $\begin{array}{c}\text { Yes } \\
(\mathrm{P}<0.01)\end{array}$ & NA \\
\hline
\end{tabular}




\section{In Vitro Flow Chamber Assay}

Flow chamber results corroborated the flow cytometry data and gave a functional tool to study the importance of these molecules on the interaction between the endothelial cells and the leukocytes. In order to verify the presence of the ligands of E-Selectin and ICAM-1 on HL60 cells, flow cytometry was utilized.

\section{Flow cytometry on HL60 cells:}

HL60 cells were found to possess the E-selectin ligand; SLe ${ }^{\mathrm{x}}$ and PSGL-1 (Figure 4-11) and the corresponding ligand for ICAM-1; LFA-1 and the $\beta_{2}$ chain of the integrins (Figure 4-12). Mac-1 was not observed on HL60 cells (Figure 4-12).

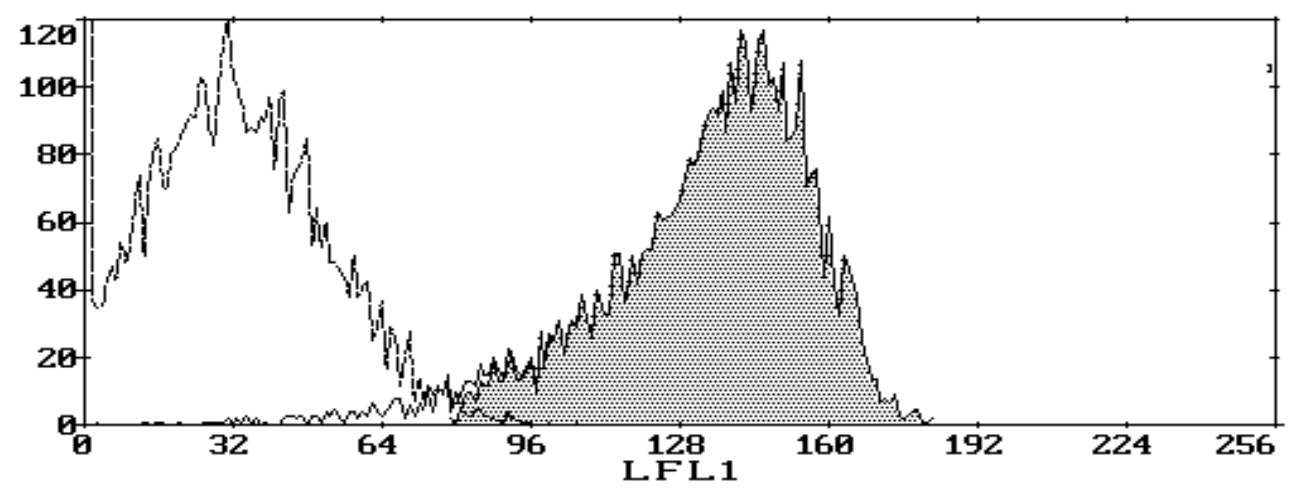

(a)

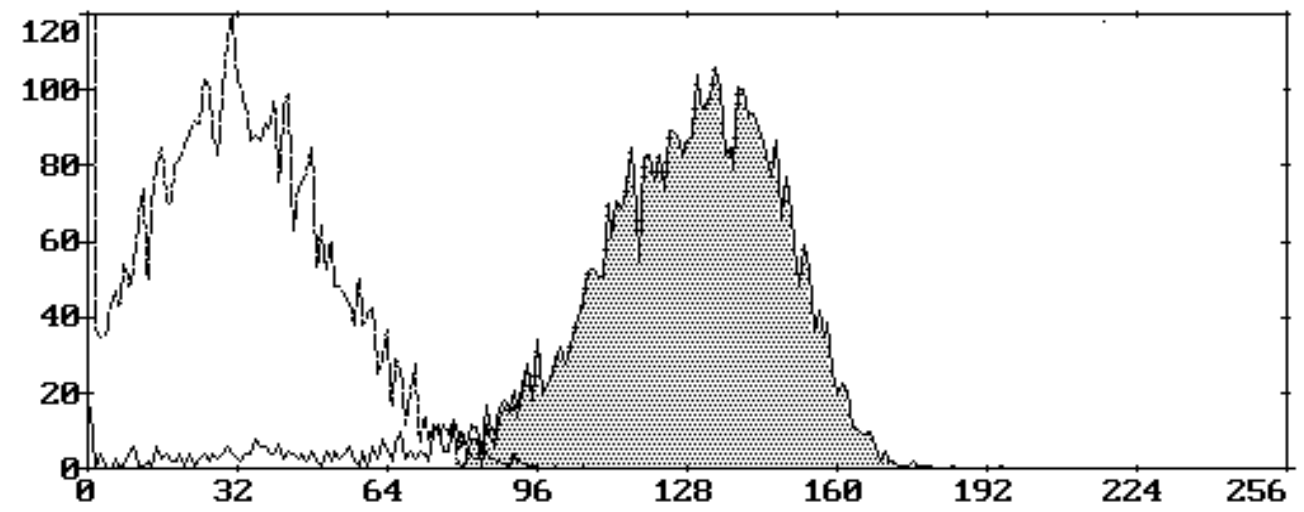

(b)

Figure 4-11. Flow cytometry plots for the expression of ligand of E-selectin on HL60 cells.

(a). PSGL-1 expression, (b). SLe ${ }^{\mathrm{x}}$ expression 


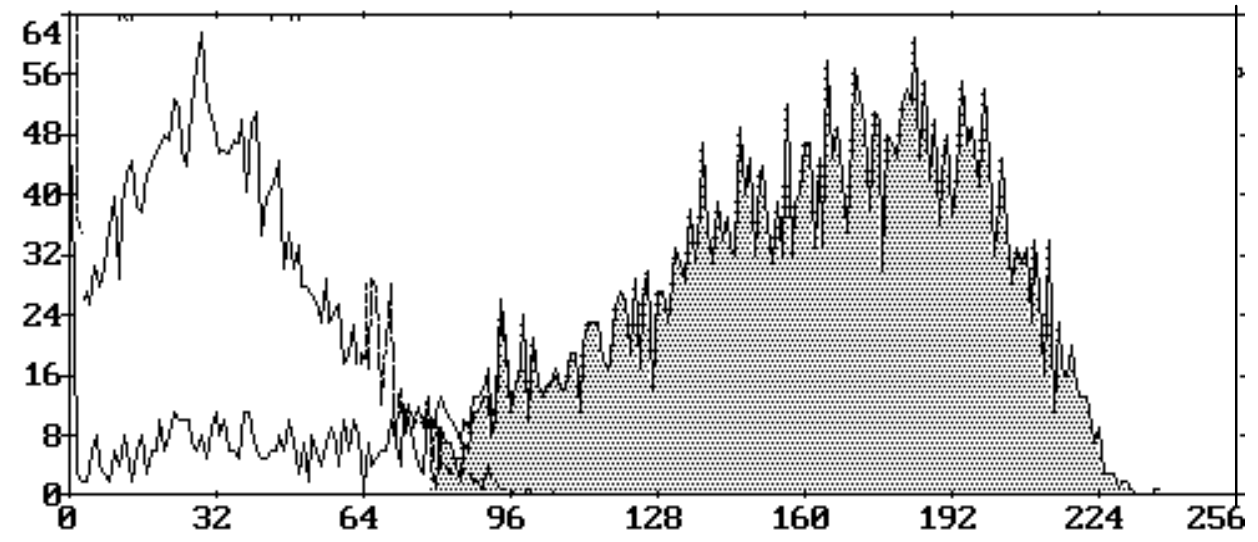

(a).

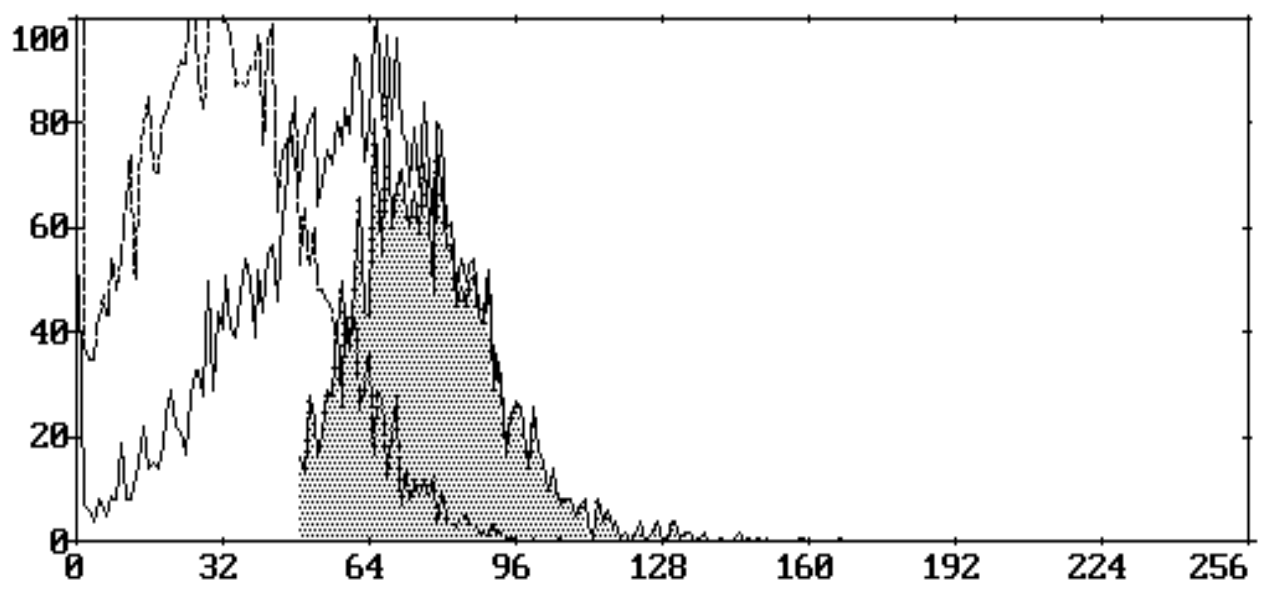

(b)

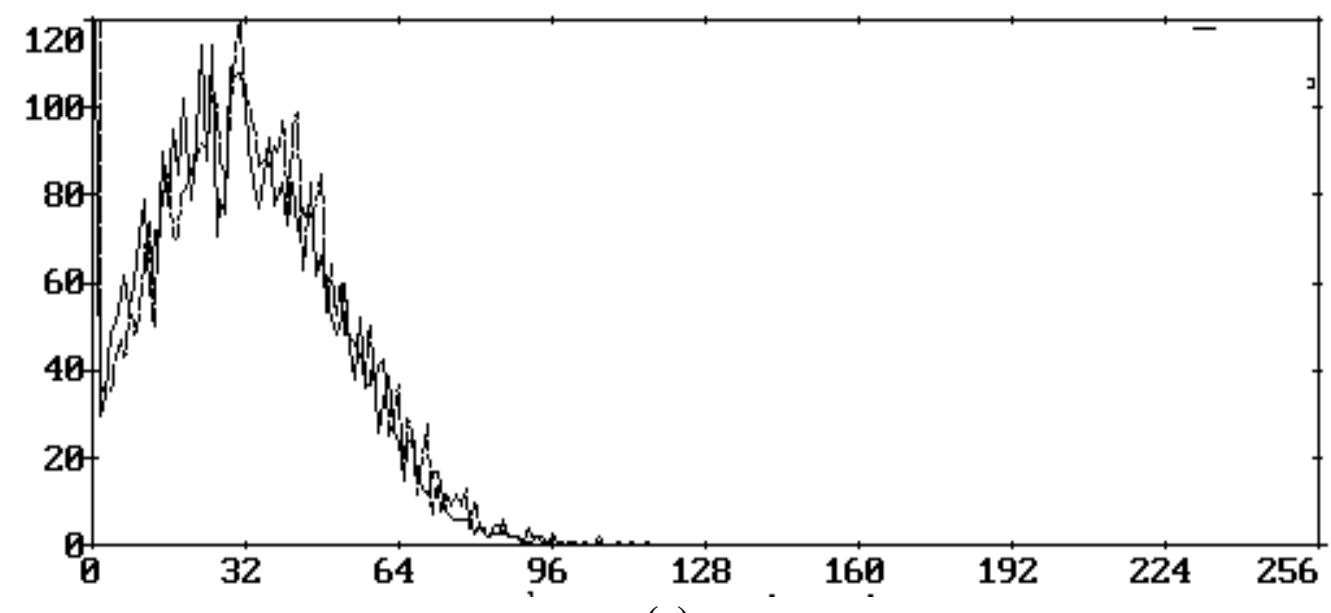

(c)

Figure 4-12. Flow cytometry plot for the expression of ligands of ICAM-1 on HL60 cells. (a). $\beta_{2}$ expression, (b). LFA-1 expression, (c). Mac-1 expression. 
For the flow assays, HL60 cells were perfused over endothelial cells (Non-Irradiated, Irradiated and IL-1 $\beta$ activated) at shear stress values of $0.5-2.0$ dynes $/ \mathrm{cm}^{2}$ in an in vitro parallel plate flow chamber and the number of rolling and adherent HL60 cells were quantified off line as indicated in methods section.

\section{Interaction of HL60 cells with HUVECs under conditions of flow:}

HL60 cells did not roll on $5 \mathrm{hr}$ control and post-irradiated HUVECs (Table 4.2).

However, HL60 cells rolled and adhered at $5 \mathrm{hr}$ post-IL1 $\beta$ activated cells and the number varied inversely with shear stress (Table 4-2 and Figure 4-13). This observation corroborated the absence of E-selectin upregulation post-irradiation. HL60 cells also did not roll and adhere at 24 hr post-irradiated HUVECs. The number of HL60 cells rolling and adhering at $24 \mathrm{hr}$ post-IL1 $\beta$ activated cells also decreased.

Table 4-2. Number of rolling and adherent HL60 cells on $5 \mathrm{hr}$ post-IR (10 Gy) HUVECs

\begin{tabular}{|c|c|c|c|c|c|c|}
\hline \multirow[t]{2}{*}{$\begin{array}{l}\text { Shear Stress } \\
(\text { dynes/cm²) }\end{array}$} & \multicolumn{2}{|c|}{ Control } & \multicolumn{2}{|c|}{ Irradiated (10 Gy) } & \multicolumn{2}{|c|}{$\begin{array}{l}\text { IL-1 } \beta \text { Activated } \\
\text { HUVECs } \\
\text { Number Of Cells }\end{array}$} \\
\hline & Rolling & Adhering & Rolling & Adhering & Rolling & Adhering \\
\hline 0.5 & 0 & 0 & 0 & 0 & $85.2 \pm 2.0$ & $80.0 \pm 3.2$ \\
\hline 1.0 & 0 & 0 & 0 & 0 & $70.0 \pm 1.5$ & $61.0 \pm 4.3$ \\
\hline 1.5 & 0 & 0 & 0 & 0 & $42.3 \pm 1.7$ & $37.0 \pm 3.0$ \\
\hline 2.0 & 0 & 0 & 0 & 0 & $34.7 \pm 0.8$ & $17.3 \pm 2.0$ \\
\hline
\end{tabular}

Notes: $\mathrm{N}=5$, Mean \pm SEM, $\mathrm{P}<0.01$ for differences between control and IL-1 $\beta$. 


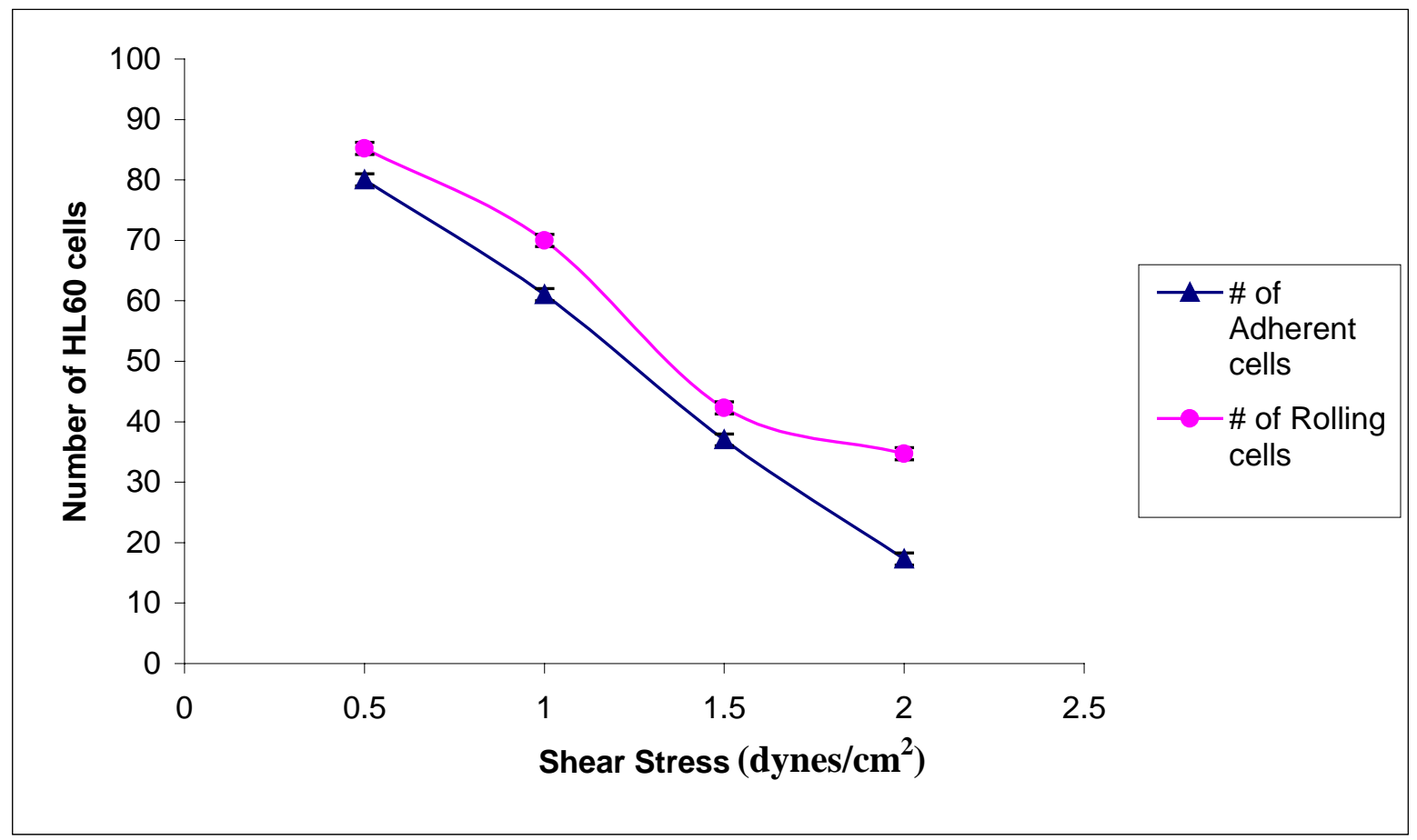

Figure 4-13. HL 60 cells rolling and adhering on $5 \mathrm{hr}$ post-IL-1 $\beta$ HUVECs. $\mathrm{N}=5$, Mean \pm SEM

Semi-static flow assay at $48 \mathrm{hr}$ post-irradiation performed by introducing HL60 cells into the flow chamber, stopping the flow, incubating for 15 minutes, and reintroducing the flow at shear stress of 0.5 and 1.0 dynes $/ \mathrm{cm}^{2}$ revealed an increase in the number of adherent cells compared to controls (Table 4-3). At shear stress of higher than 1.0 dynes $/ \mathrm{cm}^{2}$, the endothelial cell started to dissociate from the tissue culture dishes. IL-1 $\beta$ activated cells showed a significantly higher statistical difference for the number of adherent cells. The adherent cells varied inversely with the shear stress as before. At $72 \mathrm{hr}$ post-irradiation, endothelial cells started to peel of as the flow was introduced. Hence, the number of rolling or adherent HL60 cells could not be quantified at this time point. 
Table 4-3. Number of adherent HL60 cells on 48 hr post-IR (10 Gy) HUVECs.

\begin{tabular}{||c|c|c|c||}
\hline \hline $\begin{array}{c}\text { Shear Stress } \\
\left(\mathbf{d y n e s} / \mathbf{c m}^{\mathbf{2}}\right)\end{array}$ & Control & Irradiated (10 Gy) & $\begin{array}{c}\text { IL-1 } \beta \text { Activated } \\
\text { HUVECs } \\
\text { Number Of Cells }\end{array}$ \\
\hline 0.5 & $5.3 \pm 0.8$ & $16.3 \pm 1.7$ & $26.4 \pm 1.7$ \\
\hline 1.0 & $4.3 \pm 0.8$ & $11.7 \pm 0.7$ & $22.4 \pm 1.7$ \\
\hline \hline
\end{tabular}

Notes: Mean \pm SEM, $\mathrm{N}=4, \mathrm{P}<0.01$ for differences between control and irradiated.

\section{Interaction of HL60 cells with HMEC-1 under conditions of flow:}

Only 5hr post-irradiation flow assay was performed on HMEC-1. HL60 cells did not roll or adhere on $5 \mathrm{hr}$ post-activated cells. Consistent with the absence of E-selectin on HMEC-1 as observed by flow cytometry, HL60 cells failed to roll and adhere on IL-1 $\beta$ activated HMEC-1 (data not shown).

\section{Interaction of HL60 cells with HDMECs under conditions of flow:}

5hr post-irradiation flow assay on HDMECs revealed an increase in the number of rolling (Figure 4-14) and adherent cells (Figure 4-15) and the number varied inversely with shear stress. On control HDMECs also, there was a significant amount of rolling and adhering of HL60 cells, which was evident at shear stress of 1.5 dynes $/ \mathrm{cm}^{2}$. The number of rolling and adherent HL60 cells increased as the shear stress was reduced to 1.0 and 0.5 dynes $/ \mathrm{cm}^{2}$. However, at 2.0 dynes $/ \mathrm{cm}^{2}$, there was no significant difference $(\mathrm{P}>0.05)$ between the irradiated and control groups. IL-1 $\beta$ activated HDMECs showed the maximum number of HL60 cells rolling and adhering (Figure 4-14, 4-15). The data is summarized in table 4-4. 


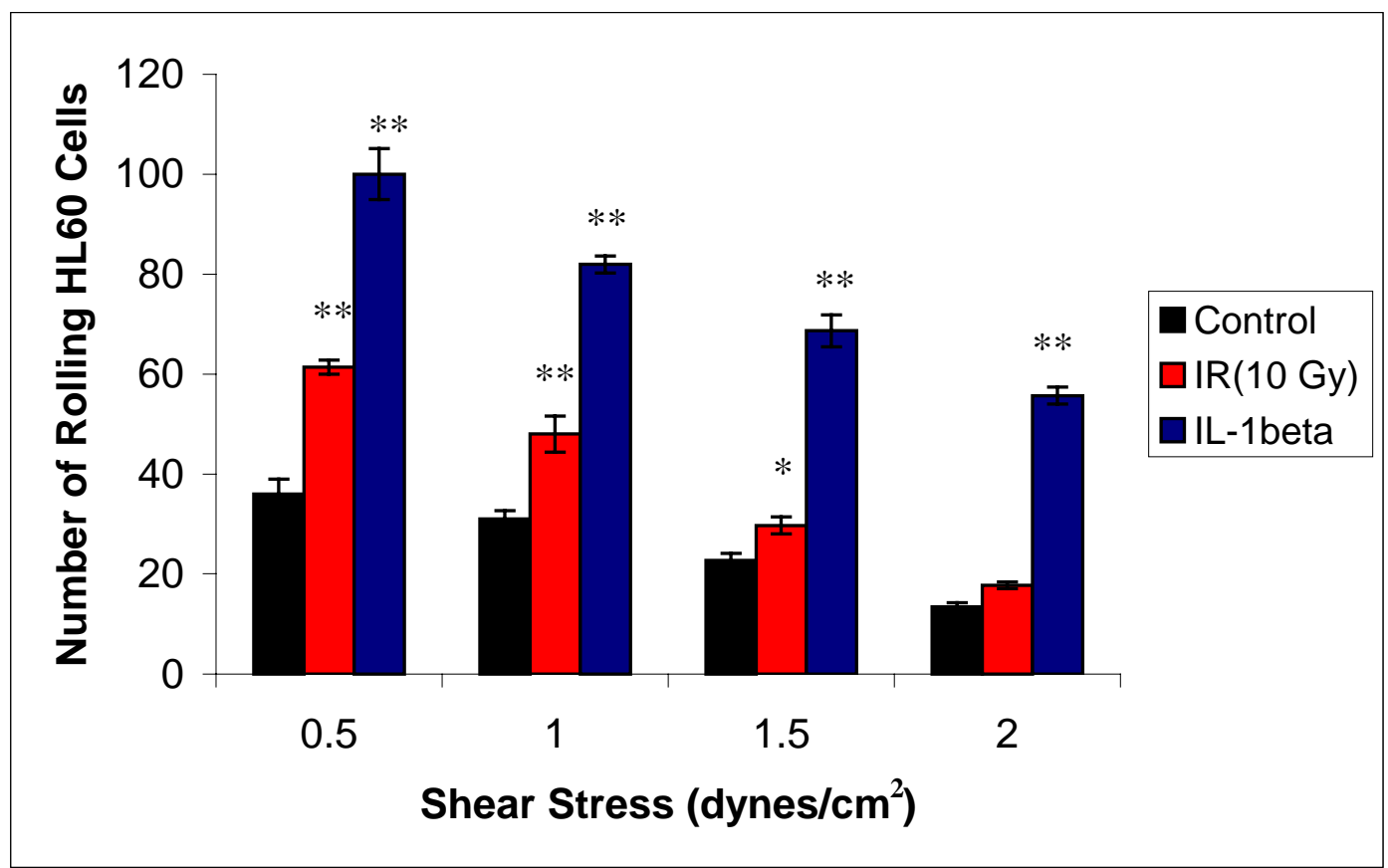

Figure 4-14. HL60 cells rolling on $5 \mathrm{hr}$ post-IR (10 Gy) HDMECs. N=3, Mean \pm SEM, $\mathrm{P}<0.05$ (control vs. IR or IL-1 beta), $\mathrm{P}<0.01$ (control vs. IR or IL-1 beta)

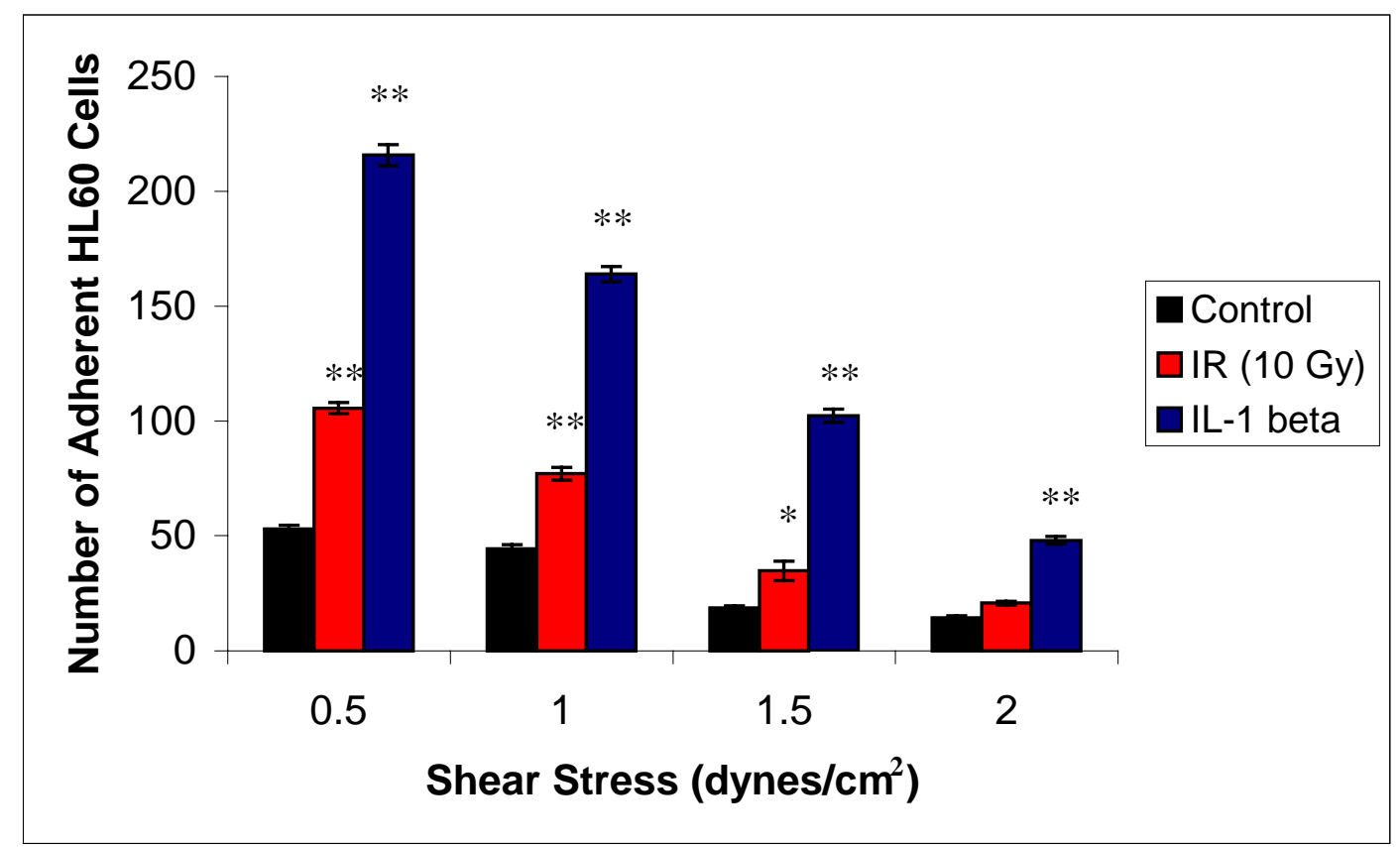

Figure 4-15. HL60 cells adhering on $5 \mathrm{hr}$ post-IR (10 Gy) HDMECs. N=3, Mean \pm SEM, $\mathrm{P}<0.05$ (control vs. IR or IL-1 beta), $\mathrm{P}<0.01$ (control vs. IR or IL-1 beta) 
Table 4-4. HL60 cells rolling and adhering on $5 \mathrm{hr}$ post-IR (10 Gy) HDMECs.

\begin{tabular}{|c|c|c|c|c|c|c||}
\hline \hline $\begin{array}{c}\text { Shear Stress } \\
\left(\mathbf{d y n e s} / \mathbf{c m}^{2}\right)\end{array}$ & \multicolumn{2}{|c|}{$\begin{array}{c}\text { Control } \\
\text { Number Of Cells }\end{array}$} & \multicolumn{2}{c|}{$\begin{array}{c}\text { Irradiated (10 Gy) } \\
\text { Number Of Cells }\end{array}$} & \multicolumn{2}{c|}{$\begin{array}{c}\text { IL-1 } \beta \text { Activated } \\
\text { Number Of Cells }\end{array}$} \\
\hline & Rolling & Adhering & Rolling & Adhering & Rolling & Adhering \\
\hline 2.0 & $13.4 \pm 0.8$ & $12.3 \pm 0.8$ & $17.7 \pm 0.7$ & $15.7 \pm 0.8$ & $55.7 \pm 1.7$ & $48.0 \pm 1.7$ \\
\hline 1.5 & $22.67 \pm 1.4$ & $18.6 \pm 0.8$ & $29.7 \pm 1.7$ & $34.7 \pm 4.2$ & $68.7 \pm 3.2$ & $102.3 \pm 2.8$ \\
\hline 1.0 & $31.0 \pm 1.7$ & $44.3 \pm 1.8$ & $48 \pm 3.6$ & $77 \pm 2.8$ & $82.0 \pm 1.7$ & $164.0 \pm 3.4$ \\
\hline 0.5 & $36 \pm 3.0$ & $53.0 \pm 1.5$ & $61.4 \pm 1.4$ & $105.6 \pm 2.4$ & $100 \pm 5.1$ & $215.7 \pm 4.6$ \\
\hline
\end{tabular}

Notes: Mean \pm SEM, $\mathrm{P}<0.05$ and $\mathrm{P}<0.01$ for differences between Control and Irradiated.

\section{Comparison of Different Doses}

In order to investigate the dose dependence on the expression of adhesion molecules, studies were conducted on HUVECs at $48 \mathrm{hr}$ and $72 \mathrm{hr}$ post-irradiation (5 Gy) to compare the expression of ICAM-1. There was a no significant difference $(\mathrm{P}>0.05)$ at $48 \mathrm{hr}$ post-IR between the two groups (5 Gy vs. $10 \mathrm{~Gy}$ ). However, at $72 \mathrm{hr}$ post-IR, a statistically significant difference $(\mathrm{P}<0.05)$ was observed on the expression of ICAM-1 (Figure 4-16).

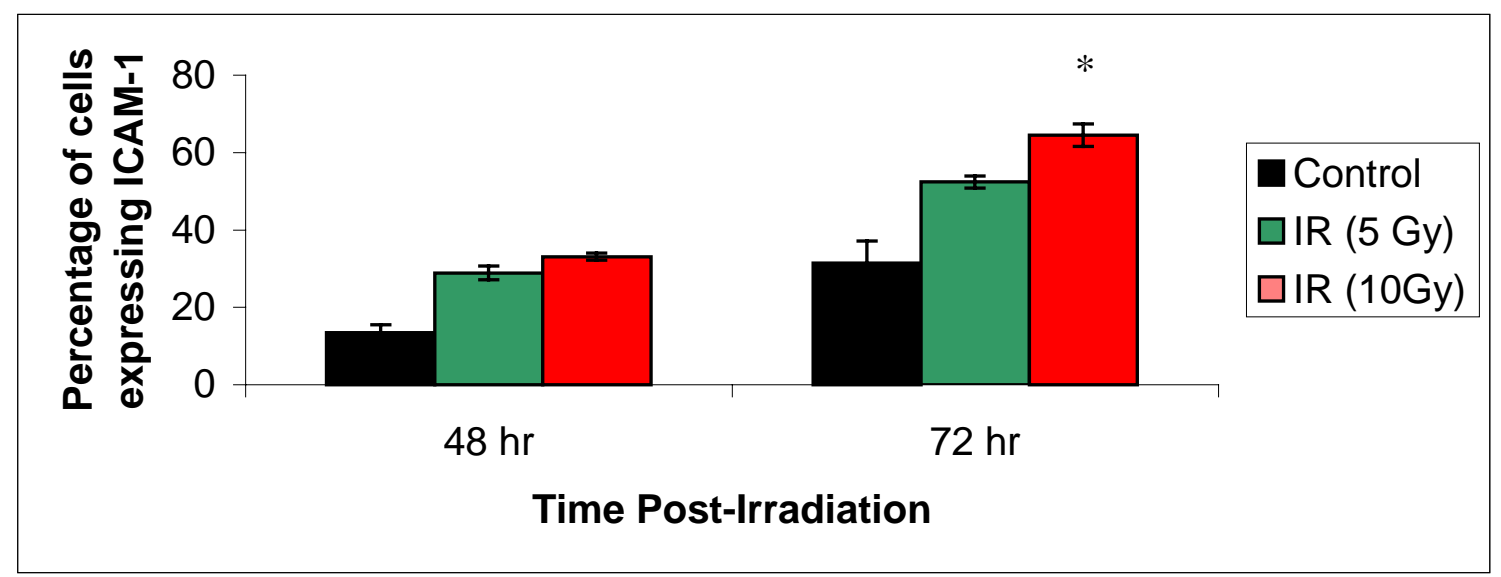

Figure 4-16. Effect of dose on the expression of ICAM-1 post-IR on HUVECs.

$$
\mathrm{N}=3 \text {, Mean } \pm \mathrm{SEM}, \mathrm{P}<0.05 \text { (5 Gy vs. } 10 \mathrm{~Gy} \text { ) }
$$




\section{Chapter 5. DISCUSSION}

Normal tissue damage is a side effect of radiation therapy. The effects of radiation were studied on endothelial cells derived from a large vessel (HUVEC) and a small vessel (HDMEC) and the transformed dermal microvascular endothelial cell line (HMEC-1). Expression of adhesion molecules was quantified by flow cytometry. The functional significance of the upregulation of the adhesion molecules was investigated in an in vitro flow chamber using shear stress values comparable to those observed in the post-capillary venules.

Our findings suggest that ionizing radiation selectively impacts the functional aspects of the inflammatory response. Endothelial cells were found to have differences in the basal level expression of adhesion molecules based on their origin; the most surprising finding was the fact that HDMECs possessed a basal level of E-selectin). Endothelial cells differed in the upregulation of adhesion molecules in a time and radiation dose dependent manner. The mode of radiation (x-ray vs. gamma) did not cause significant changes $(\mathrm{P}>0.05)$ in the upregulation of adhesion molecules. HL60 cells rolled and adhered on the endothelial cells depending on the presence of adhesion molecules: E-selectin and ICAM-1.

\section{Comparison of Control Data with Literature}

There has been many studies to quantify the expression of adhesion molecules following activation with IL-1, TNF- $\alpha$ and LPS $(9,10,11,62,72)$. A few studies $(16,27,51,50,52)$ have also investigated the effects of these adhesion molecules on the interaction of the leukocytes to the activated endothelium under flow following activation with IL-1. Our results regarding the upregulation of adhesion molecules (basal level and upregulation with IL-1 $\beta$ ) are in good agreement with the previously published results using IL-1 or TNF- $\alpha$ as the inflammatory agent 
$(74,73)$. Although, in our studies we used $10 \mathrm{U} / \mathrm{ml}$ of IL-1 $\beta$, and other investigators have used upto $500 \mathrm{U} / \mathrm{ml}$, our results agree with the time course of the upregulation of the molecules also.

All the endothelial cells had a basal level of ICAM-1 consistent with previously published results $(31,42)$. The only interesting deviation from the data in the literature is the finding that HDMEC cells possess a basal level of E-selectin. According to the available literature, this is the first time that HDMECs or any endothelial cells has been found to have a basal level of E-selectin expression. This surprising feature could be due to differences in the processing of cells that could have turned on the E-selectin gene to produce the molecule. There is a second possibility that HDMECs do have a basal level of E-selectin, which so far no one has observed. The HDMECs used in our study were obtained from neonatal foreskins. Previously published data on HDMECs obtained from the mammary skins (47), pulmonary microvascular endothelial cells (32) and from the neonatal foreskins did not show any basal level of E-selectin (20,75). However, In vivo, investigators have seen a basal level of E-selectin (67).

\section{Effects of Ionizing Radiation}

In the last 5 years, there has been several investigations of the expression of adhesion molecules following radiation $(36,37,39,38,41,40,42,31,30)$. However, there has been inconsistent data in the literature regarding the upregulation of the adhesion molecules. In addition, although static adhesion studies have been performed, no study has looked into the adhesion of leukocytes in a dynamic situation under conditions of flow. This study is the first to use a dynamic flow system to study the interaction of the HL60 cells to endothelial cells following ionizing radiation in order to investigate the functional significance of the presence of adhesion molecules on the endothelium following ionizing radiation. 
The endothelial cell morphology changed following irradiation. Cells started to became more elongated and irregular in shape by $48 \mathrm{hr}$ post-irradiation and by $72 \mathrm{hr}$ almost all the cells assumed the irregular shape. At $72 \mathrm{hr}$, a fraction of the endothelial cells started to peel off from the culture dishes leaving gaps in the confluent monolayers. However, the control (non-irradiated cells) remained firmly adhered. This is in agreement with other findings that endothelial cells tend to change their morphology by becoming more irregular in shape following irradiation (5). Loss of endothelial cells from vessels in vivo following radiation has also been reported (5).

All the endothelial cells exhibited different type of expression of adhesion molecules following ionizing radiation. E-selectin was significantly upregulated at $5 \mathrm{hr}$ post-irradiation by HDMECs. The level of expression of E-selectin on irradiated HDMECs (17\%) had approximately a 2.5 fold increase compared to that of controls $(7 \%)$.

There has been only one previous study on the expression of E-selectin following ionizing radiation (42) on HDMECs. Their results show that E-selectin mRNA was strongly induced at $24 \mathrm{hr}$ post-irradiation. However, they did not investigate the cell surface expression of E-selectin following ionizing radiation. The same group of investigators showed E-selectin expression at the cell surface was upregulated $6 \mathrm{hr}$ post-UV radiation (43). Although, we do not know how much correlation is there between UV and ionizing radiation mediated activation, our data is in good agreement regarding the time point of upregulation of E-selectin.

HUVECs did not express E-selectin following ionizing radiation. Previously published works in the literature suggest both presence $(35,36,37,41)$ as reported by Hallahan et al. and absence of E-selectin following ionizing radiation as reported by Gaugler et al (31). The rationale for the difference between their findings was based on the radiation source (x-ray vs. gamma). However, our study showed that the radiation source did not cause significant 
differences in the upregulation of adhesion molecules $(\mathrm{P}>0.05)$. Our data agrees with the published work (31) that E-selectin is not upregulated on HUVECs following ionizing radiation exposure.

HMEC-1 also did not express E-selectin following ionizing radiation. This is in agreement with previously published results using UV radiation (67). Interestingly, even after activation with IL-1 $\beta$, E-selectin was not upregulated. HMEC-1 is the immortalized transformed progeny of HDMECs. These data suggest that the immortalized transformed cell probably lose their ability to express some adhesion molecules.

We used HL60 cells as a substitute for leukocytes to study the functional interactions with the endothelium. HL60 cells possess the primary counter ligands of E-selectin and ICAM-1, namely PSGL-1, Sle ${ }^{\mathrm{x}}, \beta_{2}$ integrins and LFA-1 that are present on the leukocytes. HL60 cells did not roll or adhere on $5 \mathrm{hr}$ and $24 \mathrm{hr}$ post-irradiated HUVECs and HMEC-1 confirming the absence of E-selectin. Hallahan et al. have performed static assays (incubating the irradiated, at 5 hr post-IR HUVECs with HL60 cells) and observed a significant increase in adherent HL60 cells (36). Our results do not agree with their data. ICAM-1 is needed for firm arrest of HL60 cells on the endothelial cells. Since in their studies also they observed ICAM-1 expression only at $16 \mathrm{hrs}$ post-IR, it is difficult to visualize their results. We performed a semi-static flow assay on $5 \mathrm{hr}$ post-IR HUVECs by starting the flow, allowing the HL60 cells to interact with the endothelial cells, incubating the HL60 cells for 5 minutes and restarting the flow. Our results did not show any adherent HL60 cells. However, HL60 cells did roll and adhere on IL-1 $\beta$ activated HUVECs. These data suggest that E-selectin is not upregulated by ionizing radiation on HUVECs (in agreement with Gaugler et al.) and HMEC-1 (in contrast to Hallahan et al.) 
Flow assays on $5 \mathrm{hr}$ post-IR HDMECs revealed an increase in the number of rolling and adhering cells and the number varied inversely with shear stress. However, significant differences $(\mathrm{P}<0.05)$ were observed only at shear stress of 1.5 dynes $/ \mathrm{cm}^{2}$ or less. At 2.0 dynes/ $\mathrm{cm}^{2}$, there was no significant difference $(\mathrm{P}>0.05)$ between control and irradiated HDMECs. There was a significant amount of rolling on non-activated HDMECs corroborating our findings of small amount of basal E-selectin being present in a persistent manner. IL-1 $\beta$ activated HDMECs showed the maximum number of rolling and adherent leukocytes.

ICAM-1 was upregulated on all the three-endothelial cell types. On HUVECs, ICAM-1 was upregulated $48 \mathrm{hr}$ post-irradiation. This observation is again in contrast and agreement with published data. Our findings does not agree with the observations of Hallahan et al. that ICAM-1 is upregulated as early as $16 \mathrm{hrs}$ post-irradiation on HUVECs (36). However, we observed the upregulation of ICAM-1 at the same time point as observed by Gaugler et al. (31).

In HMEC-1 also, ICAM-1 was upregulated at $48 \mathrm{hr}$ post-irradiation. This is also in contrast to the previously published results where ICAM-1 was upregulated by $24 \mathrm{hr}$ postirradiation using UV radiation (67).

However, on HDMECs, ICAM-1 was upregulated as early as $24 \mathrm{hr}$ post-irradiation. This is in agreement with the ICAM-1 mRNA levels upregulation observed in previous studies (42). Our findings, however is the first study to report the cell surface expression of ICAM-1 on HDMECs following radiation.

On $48 \mathrm{hr}$ post-IR HUVECs, following a semi-static assay, there was a significant amount $(\mathrm{P}<0.05)$ of HL60 cells adhering to the irradiated HUVECs compared to control. There is data in the literature by Hallahan et al. showing increased adhesion of HL60 cells to HUVECs $24 \mathrm{hr}$ post-IR (36). However, our experimental time point is different from their studies (48 hr vs. 24 
hr post-IR). Static assays need ICAM-1 to mediate firm adhesion. Since in our studies ICAM-1 was upregulated only at $48 \mathrm{hr}$ post-IR, we used the $48 \mathrm{hr}$ time point.

The increase in the number of HL60 cells rolling and adhering on irradiated HDMECS but not on HUVECs and the selective upregulation of adhesion molecules on endothelial cells suggest that the response of radiation damage on endothelial cells from different parts of the body will differ. Our findings are consistent with previous studies showing that endothelial cells of the body differ from each other based on their origin.

Based on our studies, HDMECs are probably the most sensitive to radiation damage, or in other words, microvasculature of the body is most sensitive to radiation damage. Since HUVECs are from large vessels and HDMECs from small vessels, it may be justifiable to suggest that microvessels may be the primary site of increased leukocyte-endothelial interaction leading to tissue damage following radiation. It has also been shown previously that the Eselectin expression persists at a higher level on HDMECs compared to HUVECs at $24 \mathrm{hr}$ postactivation (47). This could probably help the leukocytes to mediate tissue damage for longer duration of time.

During radiation therapy, patients are treated with fractionated doses over a period. In order to investigate the effect of radiation dose on the expression of adhesion molecules, we used the $48 \mathrm{hr}$ and $72 \mathrm{hr}$ post-IR time points on HUVECs expression of ICAM-1 for this comparative study. Although, there was no significant difference $(\mathrm{P}>0.05)$ at $48 \mathrm{hr}$ post-irradiation between the two groups ( 5 Gy or $10 \mathrm{~Gy}$ ), there was a significantly higher amount of difference at $72 \mathrm{hr}$ post-irradiation $(\mathrm{P}<0.01)$. It could be due to the fact, that the onset of radiation damage may have the same latent period irrespective of the amount of radiation damage. However, once the expression of the molecule begins, there may be a dose dependent urgency to speed up the 
expression of ICAM-1. Published data shows that at 4 days post-irradiation, the ICAM-1 levels of both 5 Gy and 10 Gy irradiated HUVECs were almost at the same level (31). This could be due to the fact that, the adhesion molecules plateau off at certain limits. Adhesion molecules may reach the limit at different time points depending upon the dose of radiation.

In brief, our study suggests a difference in the radiation damage of endothelial cells depending upon their origin. The adhesion molecules play a significant role in the tissue damage following radiotherapy. There is a dose dependent increase of adhesion molecules, which may plateau off. The mechanism of this damage is probably similar to the one following an inflammatory response in the body. Leukocytes migrate to the site of injury, roll and adhere via adhesion molecules, extravasate into the tissues and mediate damage. 


\section{Chapter 6. CONCLUSION}

This study investigated the expression of adhesion molecules on the endothelium following ionizing radiation. The functional significance of the upregulation of these adhesion molecules, and the dose dependence on the upregulation of the adhesion molecules was also investigated. These results could lead to a better understanding of the side effects of radiation therapy and may aid in minimizing these side effects.

Our results indicate that:

1. There is a difference in the response of endothelial cells to radiation damage based on their origin.

2. There is no difference in the upregulation of adhesion molecules on endothelial cells in response to $\mathrm{x}$-ray or gamma irradiation.

3. E-selectin is upregulated by ionizing radiation on HDMECs at $5 \mathrm{hr}$ post-irradiation. HDMECs possess a basal level of E-selectin.

4. ICAM-1 is upregulated on HDMECs at $24 \mathrm{hr}$ post-irradiation and increases its expression by $48 \mathrm{hr}$.

5. ICAM-1 is upregulated on HUVECs and HMEC-1 at $48 \mathrm{hr}$ post-irradiation and increases by $72 \mathrm{hr}$.

6. Transformed HDMECs (HMEC-1) do not express E-selectin under control conditions

7. HL 60 cells rolled and adhered on $5 \mathrm{hr}$ post-irradiated HDMECs in significantly larger number than on control HDMECs.

8. HL60 cells adhered in significantly larger numbers on $48 \mathrm{hr}$ post-irradiated HUVECs following a semi-static assay. 
These data suggest that endothelial cells probably respond to radiation damage in the same manner following a inflammatory response, which is initiated by the upregulation of adhesion molecules. Leukocytes then roll and adhere to the endothelium via these adhesion molecules, extravasate into the tissues and cause damage. 


\section{Chapter 7. FUTURE WORK}

1. Study the effect of antibodies in blocking the upregulation of adhesion molecules following irradiation.

2. Investigate the use of radioprotective agents to prevent the upregulation of adhesion molecules.

3. Corroborate these in vitro findings with in vivo studies. 


\section{List of References}




\section{REFERENCES}

1. Abbassi, O., Kishimoto, T.K., McIntire, L.V., Anderson, D.C. and Smith, C.W. E-selectin supports neutrophil rolling in vitro under conditions of flow. J Clin Invest 92:2719$2730,1993$.

2. American Cancer Society. Cancer Facts and Figures-1999.

3. Asada, M., Furukawa, K., Kantor, C., Gahmberg, C.G. and Kobata, A. Structural study of the sugar chains of human leukocyte cell adhesion molecules CD11/CD18. Biochemistry 30:1561-1571, 1991.

4. Baeuml, H., Behrends, U., Peter, R.U., et al. Ionizing radiation induces, via generation of reactive oxygen intermediates, intercellular adhesion molecule-1 (ICAM-1) gene transcription and NF kappa B-like binding activity in the ICAM-1 transcriptional regulatory region. Free Radic Res 27:127-142, 1997.

5. Baker, D.G. and Krochak, R.J. The response of the microvascular system to radiation: a review. Cancer Invest 7:287-294, 1989.

6. Barcellos-Hoff, M.H. How do tissues respond to damage at the cellular level? The role of cytokines in irradiated tissues. Radiat Res 150:S109-S120, 1998.

7. Barinaga, M. New type of blood vessel found in tumors [news]. Science 285:1475-1475, 1999.

8. Behrends, U., Peter, R.U., Hintermeier-Knabe, R., et al. Ionizing radiation induces human intercellular adhesion molecule-1 in vitro. J Invest Dermatol 103:726-730, 1994.

9. Bevilacqua, M.P. Endothelial-leukocyte adhesion molecules. Annu Rev Immunol 11:767804, 1993.

10. Bevilacqua, M.P., Pober, J.S., Mendrick, D.L., Cotran, R.S. and Gimbrone, M.A.J. Identification of an inducible endothelial-leukocyte adhesion molecule. Proc Natl Acad Sci U S A 84:9238-9242, 1987.

11. Bevilacqua, M.P., Stengelin, S., Gimbrone, M.A.J. and Seed, B. Endothelial leukocyte adhesion molecule 1: an inducible receptor for neutrophils related to complement regulatory proteins and lectins. Science 243:1160-1165, 1989.

12. Bishop, J.M. The molecular genetics of cancer. Science 235:305-311, 1987.

13. Brinkmann R and Lamberts HB. Radiopathology of extracellular structures. Current Topics in Radiation Research 2:279-302, 1999.

14. Brunk, D.K., Goetz, D.J. and Hammer, D.A. Sialyl Lewis(x)/E-selectin-mediated rolling in a cell-free system. Biophys J 71:2902-2907, 1996. 
15. Carlos, T.M. and Harlan, J.M. Leukocyte-endothelial adhesion molecules. Blood 84:20682101, 1994.

16. Chen, S., Alon, R., Fuhlbrigge, R.C. and Springer, T.A. Rolling and transient tethering of leukocytes on antibodies reveal specializations of selectins. Proc Natl Acad Sci U S A 94:3172-3177, 1997.

17. Cheng, K.C. and Diaz, M.O. Genomic instability and cancer: cause and effect. Cancer Cells 3:188-192, 1991.

18. Chiang, C.S., Hong, J.H., Stalder, A., Sun, J.R., Withers, H.R. and McBride, W.H. Delayed molecular responses to brain irradiation. Int J Radiat Biol 72:45-53, 1997.

19. Cornelisse, C.J. and Devilee, P. Facts in cancer genetics. Patient Educ Couns 32:9-17, 1997.

20. Cornelius, L.A., Sepp, N., Li, L.J., et al. Selective upregulation of intercellular adhesion molecule (ICAM-1) by ultraviolet B in human dermal microvascular endothelial cells. J Invest Dermatol 103:23-28, 1994.

21. Davenpeck, K.L., Steeber, D.A., Tedder, T.F. and Bochner, B.S. P- and L-selectin mediate distinct but overlapping functions in endotoxin-induced leukocyte-endothelial interactions in the rat mesenteric microcirculation. J Immunol 159:1977-1986, 1997.

22. Diamond, M.S., Garcia-Aguilar, J., Bickford, J.K., Corbi, A.L. and Springer, T.A. The I domain is a major recognition site on the leukocyte integrin Mac-1 (CD11b/CD18) for four distinct adhesion ligands. J Cell Biol 120:1031-1043, 1993.

23. Diamond, M.S. and Springer, T.A. A subpopulation of Mac-1 (CD11b/CD18) molecules mediates neutrophil adhesion to ICAM-1 and fibrinogen. J Cell Biol 120:545-556, 1993.

24. Diamond, M.S., Staunton, D.E., de Fougerolles, A.R., et al. ICAM-1 (CD54): a counterreceptor for Mac-1 (CD11b/CD18). J Cell Biol 111:3129-3139, 1990.

25. Diamond, M.S., Staunton, D.E., Marlin, S.D. and Springer, T.A. Binding of the integrin Mac-1 (CD11b/CD18) to the third immunoglobulin-like domain of ICAM-1 (CD54) and its regulation by glycosylation. Cell 65:961-971, 1991.

26. Eckhart, W. Viruses and human cancer. Sci Prog 81 ( Pt 4):315-328, 1998.

27. Finger, E.B., Puri, K.D., Alon, R., Lawrence, M.B., von Andrian, U.H. and Springer, T.A. Adhesion through L-selectin requires a threshold hydrodynamic shear. Nature 379:266-269, 1996.

28. Gallo, R.C. The first human retrovirus. Sci Am 255:88-98, 1986. 
29. Garte, S.J. and Burns, F.J. Oncogenes and radiation carcinogenesis. Environ Health Perspect 93:45-49, 1991.

30. Gaugler, M.H., Squiban, C., Claraz, M., et al. Characterization of the response of human bone marrow endothelial cells to in vitro irradiation. Br J Haematol 103:980-989, 1998.

31. Gaugler, M.H., Squiban, C., van der Meeren, A., Bertho, J.M., Vandamme, M. and Mouthon, M.A. Late and persistent up-regulation of intercellular adhesion molecule-1 (ICAM-1) expression by ionizing radiation in human endothelial cells in vitro. Int J Radiat Biol 72:201-209, 1997.

32. Gerritsen, M.E., Shen, C.P., McHugh, M.C., et al. Activation-dependent isolation and culture of murine pulmonary microvascular endothelium. Microcirculation 2:151$163,1995$.

33. Gimbrone, M.A.Jr., Cotran, R.S. and Folkman, F. Human vascular endothelial cells in culture. Growth and DNA synthesis. J.Cell Biol. 60:6731974.

34. Goetz, D.J., Greif, D.M., Ding, H., et al. Isolated P-selectin glycoprotein ligand-1 dynamic adhesion to P- and E-selectin. J Cell Biol 137:509-519, 1997.

35. Hallahan, D., Clark, E.T., Kuchibhotla, J., Gewertz, B.L. and Collins, T. E-selectin gene induction by ionizing radiation is independent of cytokine induction. Biochem Biophys Res Commun 217:784-795, 1995.

36. Hallahan, D., Kuchibhotla, J. and Wyble, C. Cell adhesion molecules mediate radiationinduced leukocyte adhesion to the vascular endothelium. Cancer Res 56:5150$5155,1996$.

37. Hallahan, D.E., Kuchibhotla, J. and Wyble, C. Sialyl Lewis X mimetics attenuate Eselectin-mediated adhesion of leukocytes to irradiated human endothelial cells. Radiat Res 147:41-47, 1997.

38. Hallahan, D.E. and Virudachalam, S. Intercellular adhesion molecule 1 knockout abrogates radiation induced pulmonary inflammation. Proc Natl Acad Sci U S A 94:64326437, 1997a.

39. Hallahan, D.E. and Virudachalam, S. Ionizing radiation mediates expression of cell adhesion molecules in distinct histological patterns within the lung. Cancer Res 57:2096-2099, 1997b.

40. Hallahan, D.E. and Virudachalam, S. Accumulation of P-selectin in the lumen of irradiated blood vessels. Radiat Res 152:6-13, 1999.

41. Hallahan, D.E., Virudachalam, S. and Kuchibhotla, J. Nuclear factor kappaB dominant negative genetic constructs inhibit X-ray induction of cell adhesion molecules in the vascular endothelium. Cancer Res 58:5484-5488, 1998. 
42. Heckmann, M., Douwes, K., Peter, R. and Degitz, K. Vascular activation of adhesion molecule mRNA and cell surface expression by ionizing radiation. Exp Cell Res 238:148-154, 1998.

43. Heckmann, M., Eberlein-König, B., Wollenberg, A., Przybilla, B. and Plewig, G.

Ultraviolet-A radiation induces adhesion molecule expression on human dermal microvascular endothelial cells. Br J Dermatol 131:311-318, 1994.

44. John HE. The Physics of Radiology. Cunningham JR. 167-216. 1983.

45. Kansas, G.S. Selectins and their ligands: current concepts and controversies. Blood 88:3259-3287, 1996.

46. Kishimoto, T.K., Larson, R.S., Corbi, A.L., Dustin, M.L., Staunton, D.E. and Springer, T.A. The leukocyte integrins. Adv Immunol 46:149-182, 1989.

47. Kluger, M.S., Johnson, D.R. and Pober, J.S. Mechanism of sustained E-selectin expression in cultured human dermal microvascular endothelial cells. J Immunol 158:887-896, 1997.

48. Kotovuori, P., Tontti, E., Pigott, R., et al. The vascular E-selectin binds to the leukocyte integrins CD11/CD18. Glycobiology 3:131-136, 1993.

49. Kureshi, S.A., Hofman, F.M., Schneider, J.H., Chin, L.S., Apuzzo, M.L. and Hinton, D.R. Cytokine expression in radiation-induced delayed cerebral injury. Neurosurgery 35:822-830, 1994.

50. Lawrence, M.B., Bainton, D.F. and Springer, T.A. Neutrophil tethering to and rolling on Eselectin are separable by requirement for L-selectin. Immunity 1:137-145, 1994.

51. Lawrence, M.B. and Springer, T.A. Leukocytes roll on a selectin at physiologic flow rates: distinction from and prerequisite for adhesion through integrins. Cell 65:859-873, 1991.

52. Lawrence, M.B. and Springer, T.A. Neutrophils roll on E-selectin. J Immunol 151:63386346, 1993.

53. Loftus, J.C. and Liddington, R.C. New insights into integrin-ligand interaction. J Clin Invest 100:S77-S81, 1997.

54. Luscinskas, F.W., Ding, H. and Lichtman, A.H. P-selectin and vascular cell adhesion molecule 1 mediate rolling and arrest, respectively, of CD4+ T lymphocytes on tumor necrosis factor alpha-activated vascular endothelium under flow. J Exp Med 181:1179-1186, 1995.

55. Luscinskas, F.W. and Gimbrone, M.A.J. Endothelial-dependent mechanisms in chronic inflammatory leukocyte recruitment. Annu Rev Med 47:413-421, 1996. 
56. Marlin, S.D. and Springer, T.A. Purified intercellular adhesion molecule-1 (ICAM-1) is a ligand for lymphocyte function-associated antigen 1 (LFA-1). Cell 51:813-819, 1987.

57. McEver, R.P. and Cummings, R.D. Role of PSGL-1 binding to selectins in leukocyte recruitment. J Clin Invest 100:S97-103, 1997.

58. Miller, E.C. and Miller, J.A. Mechanisms of chemical carcinogenesis. Cancer 47:10551064, 1981.

59. Moore, K.L., Patel, K.D., Bruehl, R.E., et al. P-selectin glycoprotein ligand-1 mediates rolling of human neutrophils on P-selectin. J Cell Biol 128:661-671, 1995.

60. Morandini, R., Ghanem, G., Portier-Lemarié, A., Robaye, B., Renaud, A. and Boeynaems, J.M. Action of cAMP on expression and release of adhesion molecules in human endothelial cells. Am J Physiol 270:H807-H816, 1996.

61. Morgan, G.W. and Breit, S.N. Radiation and the lung: a reevaluation of the mechanisms mediating pulmonary injury. Int J Radiat Oncol Biol Phys 31:361-369, 1995.

62. Osborn, L., Vassallo, C. and Benjamin, C.D. Activated endothelium binds lymphocytes through a novel binding site in the alternately spliced domain of vascular cell adhesion molecule-1. J Exp Med 176:99-107, 1992.

63. Panés, J., Anderson, D.C., Miyasaka, M. and Granger, D.N. Role of leukocyte-endothelial cell adhesion in radiation-induced microvascular dysfunction in rats.

Gastroenterology 108:1761-1769, 1995.

64. Patel, K.D., Moore, K.L., Nollert, M.U. and McEver, R.P. Neutrophils use both shared and distinct mechanisms to adhere to selectins under static and flow conditions. J Clin Invest 96:1887-1896, 1995.

65. Picker, L.J., Warnock, R.A., Burns, A.R., Doerschuk, C.M., Berg, E.L. and Butcher, E.C. The neutrophil selectin LECAM-1 presents carbohydrate ligands to the vascular selectins ELAM-1 and GMP-140 [published erratum appears in Cell 1991 Dec 20;67(6):1267]. Cell 66:921-933, 1991.

66. Pober, J.S., Slowik, M.R., De Luca, L.G. and Ritchie, A.J. Elevated cyclic AMP inhibits endothelial cell synthesis and expression of TNF-induced endothelial leukocyte adhesion molecule-1, and vascular cell adhesion molecule-1, but not intercellular adhesion molecule-1. J Immunol 150:5114-5123, 1993.

67. Rhodes, L.E., Joyce, M., West, D.C., Strickland, I. and Friedmann, P.S. Comparison of changes in endothelial adhesion molecule expression following UVB irradiation of skin and a human dermal microvascular cell line (HMEC-1). Photodermatol Photoimmunol Photomed 12:114-121, 1996. 
68. Rubin, P., Johnston, C.J., Williams, J.P., McDonald, S. and Finkelstein, J.N. A perpetual cascade of cytokines postirradiation leads to pulmonary fibrosis [see comments]. Int J Radiat Oncol Biol Phys 33:99-109, 1995.

69. Shattil, S.J. and Ginsberg, M.H. Perspectives series: cell adhesion in vascular biology. Integrin signaling in vascular biology. J Clin Invest 100:1-5, 1997.

70. Slack, S.M., Cui, Y. and Turitto, V.T. The effects of flow on blood coagulation and thrombosis. Thromb Haemost 70:129-134, 1993.

71. Sporn, L.A., Shi, R.J., Lawrence, S.O., Silverman, D.J. and Marder, V.J. Rickettsia rickettsii infection of cultured endothelial cells induces release of large von Willebrand factor multimers from Weibel-Palade bodies. Blood 78(10):2595-2602, 1991.

72. Springer, T.A. Adhesion receptors of the immune system. Nature 346:425-434, 1990.

73. Springer, T.A. Traffic signals for lymphocyte recirculation and leukocyte emigration: the multistep paradigm. Cell 76:301-314, 1994.

74. Springer, T.A. Traffic signals on endothelium for lymphocyte recirculation and leukocyte emigration. Annu Rev Physiol 57:827-872, 1995.

75. Swerlick, R.A., Garcia-Gonzalez, E., Kubota, Y., Xu, Y.L. and Lawley, T.J. Studies of the modulation of MHC antigen and cell adhesion molecule expression on human dermal microvascular endothelial cells. J Invest Dermatol 97:190-196, 1991.

76. Tannock, I.F. The Basic Science of Oncology, McGraw Hill, 1999. Ed.Third

77. Van der Vieren, M., Le Trong, H., Wood, C.L., et al. A novel leukointegrin, alpha d beta 2, binds preferentially to ICAM-3. Immunity 3:683-690, 1995.

78. Wagner, D.D., Olmsted, J.B. and Marder, V.J. Immunolocalization of von Willebrand protein in Weibel-Palade bodies of human endothelial cells. J.Cell Biol. 95:355360, 1982.

79. Williams, A.F. and Barclay, A.N. The immunoglobulin superfamily--domains for cell surface recognition. Annu Rev Immunol 6:381-405, 1988.

80. Yamamoto, T. Molecular basis of cancer: oncogenes and tumor suppressor genes. Microbiol Immunol 37:11-22, 1993. 
Appendix 


\section{Steps in Running an In Vitro Flow Chamber Assay}

1. Warm the buffer/media to $37^{\circ} \mathrm{C} 1 \mathrm{hr}$. prior to beginning flow assay.

2. Assemble flow system apparatus connecting inlet, outlet, and vacuum lines to the flow chamber deck with the help of 3-way stopcock connected to two $10 \mathrm{ml}$ syringes.

3. Apply a small amount of vacuum grease on the gasket and attach to the flow chamber. Make sure no grease was present on the side coming in contact with the cells. Smoothen the gasket so it is free from any wrinkles and leave the system undisturbed for at least one hour prior to use.

4. Fill the system with media and remove all air from system.

5. Fill inlet reservoir (usually a $10 \mathrm{ml}$ disposable syringe) with cell suspension. The cell concentration should be $10^{5}$ or $10^{6}$ cells $/ \mathrm{ml}$

6. Attach an empty $35 \mathrm{~mm}$ dish to flow chamber deck. Hold the deck inverted, place a small bubble of media on flow path area, then place the $35 \mathrm{~mm}$ dish on the deck. Switch on the vacuum. Vacuum will hold dish on deck. Make sure dish was attached with no air bubbles in the chamber.

7. Place assembled chamber on microscope stage.

8. Initiate flow of buffer/media with the syringe pump with shear stress of 0.5-1.0 dynes $/ \mathrm{cm}^{2}$ till there is no air bubble in the path.

9. Remove the dish and replace it with dish containing monolayer of cells. Initiate flow of cells syringe pump connected to outlet flow chamber at a shear stress in the range of 0.52.0 dynes $/ \mathrm{cm}^{2}$.

10. Allow cells to flow for sufficient time (3- 5 minutes) to get an adequate number of cells interacting with the cell monolayer.

11. Begin image acquisition. Collect images at 8-10 locations on the dish. Generally 3 dishes at a given experimental condition gives enough data to show statistical differences between treatments.

12. After images are acquired on all dishes, perform image analysis to quantify the flow assay using Metamorph Imaging Software. 


\section{VITA}

Balabhaskar Prabhakarpandian was born on September 6th, 1973 in Villupuram, India. Balabhaskar has an undergraduate degree in Chemistry and a MS degree in Biotechnology from the Indian Institute of Technology, Bombay, India. Balabhaskar came to the United States in fall of 1997 to pursue a MS degree in Biomedical Engineering in the Joint Program in Biomedical Engineering between The University of Tennessee and The University of Memphis. After his graduation, Balabhaskar will work in a biomedical industry developing novel products, which will utilize his expertise in Biotechnology and Engineering. 